\title{
Role of Nitrogen-Metabolism Genes Expressed During Pathogenicity of the Alkalinizing Colletotrichum gloeosporioides and Their Differential Expression in Acidifying Pathogens
}

\author{
I. Miyara, ${ }^{1,2}$ C. Shnaiderman, ${ }^{1,2}$ X. Meng, ${ }^{3}$ W. A. Vargas,,${ }^{4}$ J. M. Diaz-Minguez, ${ }^{4}$ A. Sherman, ${ }^{5}$ M. Thon, ${ }^{4}$ and \\ D. Prusky ${ }^{1}$
}

${ }^{1}$ Department of Postharvest Science of Fresh Produce, ARO, Bet Dagan, Israel; ${ }^{2}$ The Hebrew University of Jerusalem, The Robert H. Smith Faculty of Agriculture, Food and Environment, Rehovot, Israel; ${ }^{3}$ Fruit Tree Research Institute, Guangdong Academy of Agricultural Sciences, Guangzhou, China; ${ }^{4}$ Department of Microbiology and Genetics, CIALE, Universidad de Salamanca, Salamanca, Spain; ${ }^{5}$ Genomic Unit, Plant Sciences Institute, ARO, Bet Dagan, Israel

Submitted 25 January 2012. Accepted 28 April 2012.

Pathogens can actively alter fruit $\mathrm{pH}$ around the infection site, signaling modulation of pathogenicity-factor expression, as found for alkalinizing (Colletotrichum and Alternaria spp.) and acidifying (Penicillium, Botrytis, and Sclerotinia spp.) fungi. The nitrogen-metabolism genes $G D H 2, G S 1$, $G L T$, and $M E P$ genes are differentially expressed during colonization by Colletotrichum gloeosporioides, and a $\Delta g d h 2$ strain reduces ammonia accumulation and pathogenicity. We analyzed the contribution of transporters $G L T$ and $M E P B$ to $C$. gloeosporiodes pathogenicity. Germinating spores of $\Delta g l t$ strains showed reduced appressorium formation; those of $\triangle m e p B$ mutants showed rapid ammonia uptake and accumulation inside the hyphae, indicating deregulated uptake. Both mutants reduced pathogenicity, indicating that these transporters function during alkalinizing species pathogenicity. We compared the expressions of these genes in $C$. gloeosporioides and Sclerotinia sclerotiorum, and found five to $\mathbf{1 0}$-fold higher expression at the transcript level in the former. Interestingly, $G L T$ and $M E P B$ in the alkalinizing species showed no and very low sequence identity, respectively, with their counterparts in the acidifying species. Knockout analysis of $G L T$ and $M E P B$ and their differential transcript regulation in the alkalinizing and acidifying species suggest that the ammonia accumulation contributing to pathogenicity in the former is modulated by factors at the gene-regulation levels that are lacking in the acidifying species.

Colletotrichum gloeosporioides is a broad-host-range plantpathogenic fungus that alkalinizes host tissue during disease

Nucleotide sequence data can be found in the EMBL and GenBank databases under the following accession numbers: for $G L T$, JN660151; GDH2, JN660152; GS1, JN660153; MEPA, JN660155; MEPB, JN660156; $M E P C$, JN660157; and MEPD, JN660154.

I. Miyara and C. Shnaiderman contributed equally to the research presented here.

Corresponding author: D. Prusky; Telephone: 972-3-9683880; Fax: 972-39683622; E-mail: dovprusk@agri.gov.il

* The $\boldsymbol{e}$-Xtra logo stands for "electronic extra" and indicates that a supplementary table is published online. development (Prusky et al. 2001). Host alkalinization results from active secretion of ammonia induced by relatively low $\mathrm{pH}$ values, as detected in several Colletotrichum spp.-infected fruit (Alkan et al. 2008; Diéguez-Uribeondo et al. 2008; Drori et al. 2003; Kramer-Haimovich et al. 2006; Prusky and Yakoby 2003). Whereas Colletotrichum spp. (Alkan et al. 2008; Prusky et al. 2001) and Alternaria alternata (Eshel et al. 2002) alkalinize the host environment, other species belonging to genera such as Penicillium (Hadas et al. 2007; Prusky et al. 2004), Botrytis (Manteau et al. 2003; ten Have et al. 2001; Wubben et al. 2000), Sclerotinia (Rollins and Dickman 2000; Tea Kim et al. 2007), Phomopsis (Davidzon et al. 2009), and Aspergillus (Karaffa and Kubicek 2003) tend to acidify it. Thus, some pathogens have been classified as alkalinizers or acidifiers according to the $\mathrm{pH}$ changes they induce during pathogenicity (Prusky and Yakoby 2003). This differential pH modulation is not a host-mediated effect, it is pathogen dependent. The same host attacked by acidifying or alkalinizing pathogens usually has opposite responses. In all cases, however, the induction of this differential $\mathrm{pH}$ shift represents an efficient tool for that particular pathogen for activating the production and secretion of pathogenicity factors, inducing host cell death and enhanced colonization processes (Alkan et al. 2009; Dickman 2007).

Miyara and associates $(2008,2010)$ monitored gene expression during ammonia secretion and colonization of avocado fruit, by using macroarrays carrying $C$. gloeosporioides cDNA. A set of genes involved in nitrogen metabolism and modulating the synthesis and catabolism of ammonia was differentially induced under different $\mathrm{pH}$ conditions. Among those genes induced at early stages of the alkalinization process $(\mathrm{pH}$ 4.0 to 4.5 ) were $\mathrm{NAD}^{+}$-specific glutamate dehydrogenase $(G D H 2$, encoding for ammonia synthesis, JN660152) and the ammonia transporter AMET (modulated in yeast by the Ato protein). Among those induced at $\mathrm{pH} 6.0$ to 7.0 during the alkalinization process were the ammonia permeases $(M E P B$, JN660156), glutamate transporter (GLT, JN660151), and glutamine synthetase (GS1, JN660153) (Table 1). The dynamics of ammonia accumulation in C. gloeosporioides showed that, at an early stage of the alkalinization process ( $\mathrm{pH} 4.0$ to 4.5 ), the production of ammonia by $G D H 2$ expression and its export by the ammonia exporter AMET contribute to the accumulation of ammonia in the medium (Miyara et al. 2010). At increasing $\mathrm{pH}$ values ( $\mathrm{pH} 6$ to 7), increased expression of $M E P B$ 
and $G L T$, together with $G S 1$ activity, regulates the internal level of ammonia in the hyphae (Miyara et al. 2010).

Activation of nitrogen metabolism is a highly complex process involving the activation of genes that contribute to the accumulation of ammonia in the host, induction of $\mathrm{pH}$ changes, and activation of pathogenicity factors that are expressed under the newly created environmental conditions. The present work was carried out to analyze the contribution of a set of nitrogen-metabolism genes, the transporters GLT and $M E P B$, to the modulation of pathogenicity by $C$. gloeosporioides. We also confirmed, by in-depth transcriptome comparison of the alkalinizing and acidifying C. gloeosporioides and Sclerotinia sclerotiorum, respectively, the importance of differences at the sequence level in the regulation of the transporters $G L T$ and $M E P B$ in determining the differential ammonia accumulation between the two fungal species. In $C$. gloeosporioides, the alkalinization process was the result of upregulation of ammonia synthesis and metabolism genes, the presence of an active $G L T$ transporter that affects appressorium formation and pathogenicity, and a specific $M E P B$ lineage involved in ammonia export, appressorium formation, and pathogenicity, none of which were found in S. sclerotiorum.

\section{RESULTS}

Sequence and functional analysis of the GLT transporter in C. gloeosporioides.

A BLAST search of the putative GLT sequence of C. gloeosporioides against other alkalinizing species such as Fusarium oxysporum (Table 1; Fig. 1) revealed the presence of a homologous sequence with 51 to $59 \%$ similarity to the prokaryotic and eukaryotic high-affinity sodium-dependent glutamate transporters (Ren and Paulsen 2005; Ryan et al. 2009). Analysis of the putative GLT proteins displayed identical hallmark features described for high-affinity sodium-dependent glutamate transporters from eukaryotes and prokaryotes (Yernol et al. 2004):

Table 1. Pairwise sequence similarity between Colletotrichum gloeosporioides genes and homologs detected in four other species of filamentous fungi

\begin{tabular}{lcccc}
\hline Species & GDH2 & GS1 & GLT & MEPB \\
\hline Fusarium oxysporum & 76.86 & 76.52 & 59.45 & 71.31 \\
Aspergillus niger & 65.55 & 70.56 & - & 53.69 \\
Botrytis cinerea & 79.86 & 80.50 & - & 64.04 \\
Sclerotinia sclerotiorum & 71.82 & 81.97 & - & 63.71 \\
\hline
\end{tabular}

sodium-binding, potassium-coupling, and glutamate $\gamma$-carboxylate-binding sites (Fig. 1).

To assess the function of GLT in C. gloeosporioides, gene knockout was performed to generate $\Delta g l t$ strains (Fig. 2), by replacing the intact $G L T$ with a $G L T B 5^{\prime}-H y g-G L T B 3^{\prime}$ cassette, as described below (Hadas et al. 2007). Deletion of the gene was confirmed by polymerase chain reaction (PCR) (Fig. 2). Gene expression of $G L T$ was detected by quantitative reversetranscriptase (qRT)-PCR (Fig. 2B) in the wild-type (WT) progenitor strain $\mathrm{Cg}-14$ and ectopic ${ }_{10}$ strains but not in $\Delta$ glt $_{5}$, $\Delta g t_{6}$, or $\Delta g t_{31}$ strains, confirming deletion of $G L T$.

The $\Delta$ glt strains grown for three generations on $\mathrm{M}_{3} \mathrm{~S}$ medium amended with reduced nitrogen sources levels $(0.5 \mathrm{mM}$ $\mathrm{KNO}_{3}$ ) showed 37 to $56 \%$ inhibition of appressorium formation compared with the WT and ectopic strains (Fig. 3). Inoculation of avocado pericarp with strain $\Delta g t_{31}$ inhibited anthracnose symptom development by 45 to $50 \%$ compared with the WT strain 7 days after symptom appearance, suggesting that inhibition of appressorium formation affects symptom development.

Functional analysis of $C$. gloeosporioides MEPB: Effect on ammonia import/export balance and pathogenicity.

To assess the function of $M E P B$ of $C$. gloeosporioides, a gene-deletion experiment was carried out to generate $\triangle$ mep $B$ mutant strains by homologous recombination (Fig. 4), replacing the intact $M E P B$ with a $M E P B 5^{\prime}-H y g-M E P B 3^{\prime}$ deletion cassette, as described below (Shafran et al. 2008). Gene expression of $M E P B$ was detected by qRT-PCR (Fig. 4B) in the WT progenitor $\mathrm{Cg}-14$, ectopic ${ }_{5}$, and the complemented strain $\Delta m e p B_{12 \text { compl3 }}$, but not in strains $\Delta m e p B_{3}$ or $\Delta m e p B_{12}$, confirming deletion of $M E P B$.

When the 3-day hyphal mats of the $\triangle m e p B$ isolates were transferred from the initial $\mathrm{M}_{3} \mathrm{~S}$ medium to inductive secondary medium $(\mathrm{SM})$ amended with $10 \mathrm{mM} \mathrm{NH}_{4} \mathrm{Cl}$, ammonia concentration in the growth culture declined fourfold from 23 to $6 \mathrm{mM}$ ammonia per gram of dry weight of fungal mycelium $(\mathrm{mM} / \mathrm{g} \mathrm{dw}) 6 \mathrm{~h}$ postinoculation (hpi), suggesting rapid uptake, whereas minor changes were observed with the WT and ectopic strains which remained at a similar initial concentration ( 25 to $24 \mathrm{mM} / \mathrm{g} \mathrm{dw}$ ). After a further $6 \mathrm{~h}$, ammonia level in the medium declined to similar levels in all strains (Fig. 5A). Analysis of ammonia levels inside the $\triangle m e p B$ isolate, WT, and ectopic control strains showed a different pattern. Whereas the level of ammonia decreased drastically from 78 to $26 \mathrm{mM}$ in the WT and ectopic strains during the first 6 hpi (Fig. 5B), it

\begin{tabular}{|c|c|c|}
\hline PhGTL & DAMLTAFVTRSSSGTLPVTMRVA-KEMGISEGIYSFTLPLGATINMDGTALYQGVCTFFI & 325 \\
\hline GLT1 & SAGTLPVTFRCLEDNLGIDKRVTRFVLPVGATINMDGTALYEAVAAIFI & 11 \\
\hline $\begin{array}{l}\text { FoGLT } \\
\text { CglGLT }\end{array}$ & $\begin{array}{l}\text { PAWITAWGTASSAATLSVTLRCA-KDRGIPSTVYKFTCPLGCLINMDGTAIYLPAAVVFM } \\
\text { PAWLTAWGTASSAATLSVTMKCTRETLKVPNTITKFAVPLGCLVNMDGTAIYFPIVVVFL }\end{array}$ & 37 \\
\hline PhGTL & QLTIVLTAVLAS IGTAGVPGAGAIMLAMVLESVGLPI & \\
\hline GLT1 & DGGQIVTVSLTATLAS IGAAS IPSAGLVTMLLILTAVGLPTED------ISL & 46 \\
\hline FOGLT & AATQGTTLGPTDYVIVALLSTLASIGVSPIPSASLVLSIMIARSVNVDLTN-- & 12 \\
\hline CglGLT & AQTQGHVLNAADYI I ILLLSTLASIGTTP IPSSSLVLTVMISSSVGIPPSG-----MFGV & 42 \\
\hline PhGTL & UVNVTGDLTGTAIVAKTEGELEKGVIA------------------ & \\
\hline GLT1 & SVNVVGDSFGAGIVYHLSKSELDTIDSQHRMHEDIEMTKTQSVYDDT & 52 \\
\hline FOGLT & LDRFRTAVNVSGDLFASMI IYKMTKIEDPPEVVEQNAREADQSEKDASNKV-- & 47 \\
\hline glGL? & ATNVSGDLFAAVIVQKMTGITDPEDGSEDEVTEVRQNDE & \\
\hline
\end{tabular}

Fig. 1. Sequence alignment of glutamate transporters. Alignment of amino acid sequences of Pyrococcus horikoshii GLT and rat GLT1 with putative GLT sequences identified in fungi. The sequence alignment highlights (dark gray) the conserved motifs shown to be involved in glutamate binding and transport. Light gray-shaded residues indicate the conserved arginine (R) suggested to be the glutamate $\gamma$-carboxylate-binding residue in P. horikoshii GLT (Yernol et al. 2004); amino acid G, sodium binding; amino acid YQ, potassium coupling. Amino acid sequences are: P. horikoshii (Ph) GLT (NP_143181); rat GLT1 (P31596); F. oxysporum (Fo) GLT (FOXG_03264.2); and Colletotrichum gloeosporioides (Cg) GLT (JN660151). The alignment was performed using ClustalW and adjusted manually. 
remained constant (within 60 to $75 \mathrm{mM}$ ) in the $\triangle$ mep $B$ strains. After an additional $6 \mathrm{~h}$, the level of ammonia in the $\Delta m e p B$ isolates was similar to that in the control strains. This rapid change in internal ammonia level suggests deregulation and a concurrent delay in ammonia export.

Germination of $\Delta m e p B_{3}$ and $\Delta m e p B_{12}$ strains was inhibited by $35 \% 14 \mathrm{~h}$ after germination initiation but, $2 \mathrm{~h}$ later, the $\triangle m e p B, \mathrm{WT}$, and ectopic control strains showed similar germination patterns (Fig. 6A). Appressoria formation showed a $55 \%$ inhibition in the $\triangle m e p B$ isolate compared with WT and ectopic control strains (Fig. 6B). The colonization area of $C$. gloeosporioides $\Delta m e p B_{3}$ and $\Delta m e p B_{12}$ strains inoculated on peeled avocado fruit was significantly reduced compared with the WT strain (Fig. 7): 7 days after inoculation, the diameter of the mesocarp colonized by the WT and ectopic T5 $_{5}$ strains reached $21.5 \pm 0.5 \mathrm{~mm}$, whereas average colonization by the $\Delta m e p B_{3}$ and $\Delta m e p B_{12}$ mutants was only $8.0 \pm 0.1 \mathrm{~mm}$. Complemented strains did not differ from the WT in any of the experiments (data not shown).

Comparison of the ammonia metabolism-modulating genes in alkalinizing and acidifying fungal species.

Five fungal species that either alkalinize their surroundings (C. gloeosporioides and F. oxysporum f. sp. phaseoli) or acidify them via the secretion of organic acids during colonization

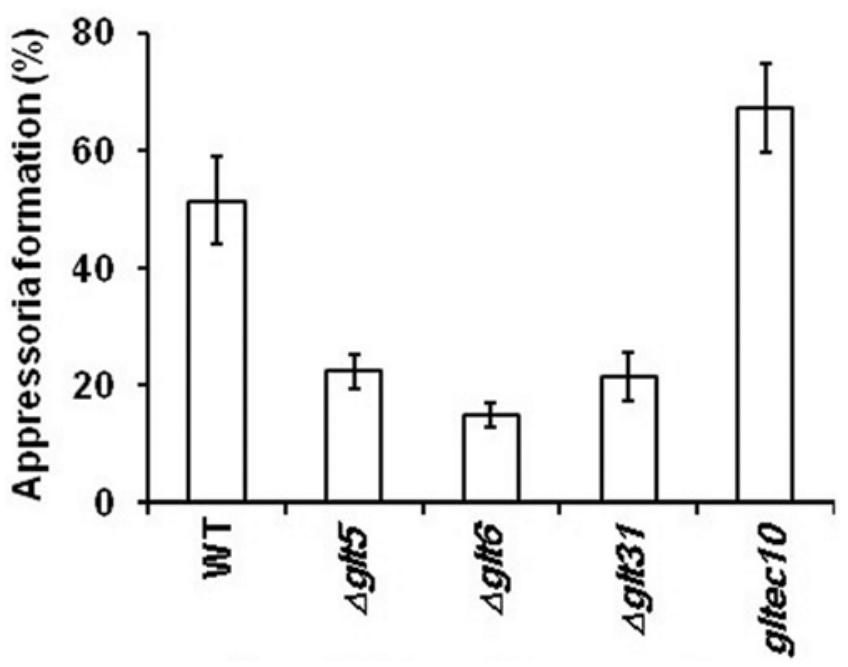

Fig. 3. Appressorium formation by germinating spores of $\Delta g l t$ strains after growth on solid MS media containing $\mathrm{KNO}_{3}$ as nitrogen source. Mycelia of the wild-type (WT) and $\Delta g l t$ strains were grown on $\mathrm{M}_{3} \mathrm{~S}$ transferred to a medium containing $0.5 \mathrm{M} \mathrm{KNO}_{3}$ as nitrogen source for three generations and 2 weeks later collected for appressorium-formation assay. Spores were brought to a concentration of $10^{6}$ spores $/ \mathrm{ml}$ and a $10-\mu l$ drop was placed on a glass slide for evaluation of appressorium formation $16 \mathrm{~h}$ later.

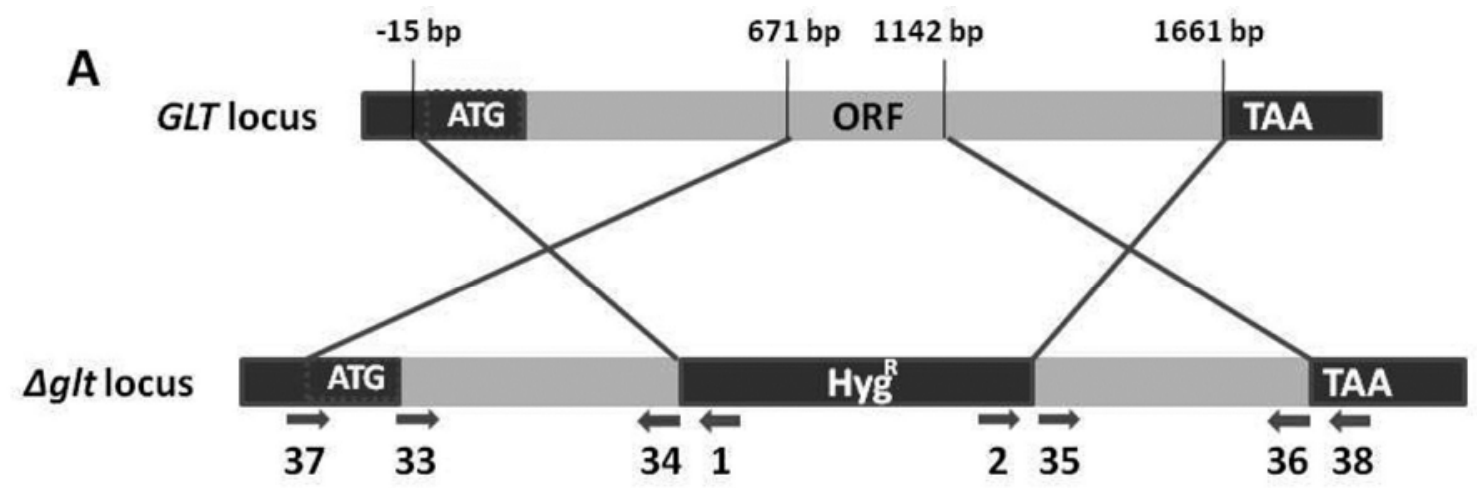

B

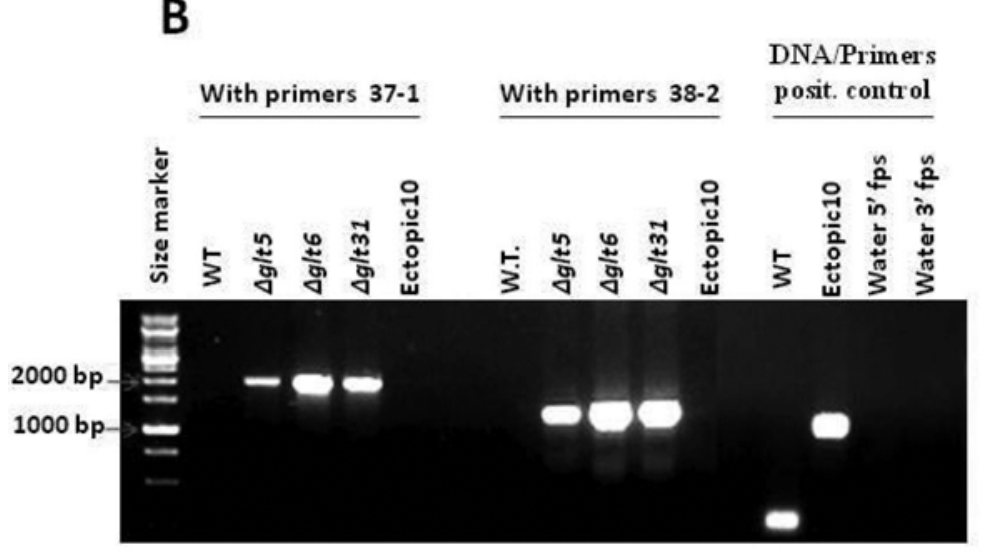

C

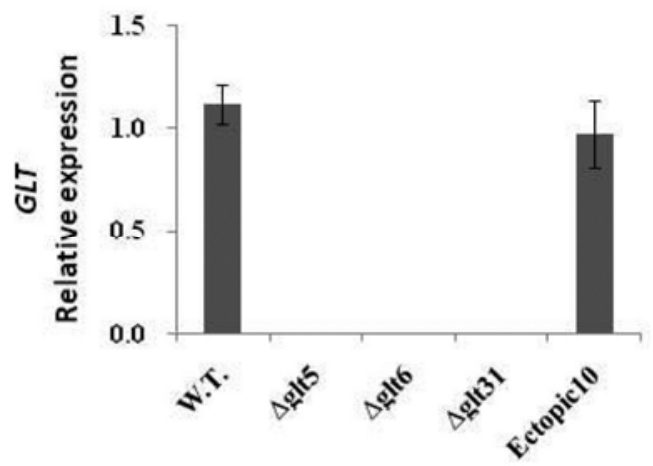

\section{C. gloeosporioides strains}

Fig. 2. Development of $G L T$ mutant strains. A double crossing-over homologous recombination event resulting in replacement of the original $G L T$ sequence with the GLT5'-Hyg-GLT3' cassette was carried. A, Scheme describing gene disruption by homologous recombination. The pairs of primers used in construct creation were 33-34 for the $5^{\prime}$ end and 35-36 for the $3^{\prime}$ end. B, Polymerase chain reaction (PCR) analysis of the wild-type (WT) strain, ectopic colony (Ectopic ${ }_{10}$ ), and independent $G L T$-disruption colonies $\left(\Delta g l t^{\top}\right)$. Primer 37 flanking a position upstream of the GLT2:HYG3 region and reverse primer 1 located on the hygromycin cassette were used to identify positive GLT gene replacement at the $5^{\prime}$ locus. Primer 38 from the hygromycin cassette and primer 2 flanking the GLT:HYG3 region were used to identify $G L T$ gene replacement at the $3^{\prime}$ locus. $18 S$ gene primers 23 and 24 were used for WT DNA quality control. Primers 1 and 33 were used as a positive control for the ectopic strains, to confirm random integration of the GLT:HYG3 cassette. C, Expression of GLT in the WT strain compared with the ectopic-integration control and the $\Delta g l t$ strains, as detected by quantitative reverse-transcriptase (qRT-)PCR. Cultures were initially grown in $\mathrm{M}_{3} \mathrm{~S}$ rich medium and were then transferred to broth minimal medium without nitrogen source for $5 \mathrm{~h}$ prior to RNA extraction. Relative expression values obtained by qRT-PCR are normalized against $18 S$ rRNA. Average \pm standard deviation from three replications of one treatment is presented. 
(Botrytis cinerea, S. sclerotiorum, and Aspergillus niger) were compared. Growth of $C$. gloeosporioides and F. oxysporum for $48 \mathrm{~h}$ on ammonia-inducing media containing $50 \mathrm{mM} \mathrm{KNO}_{3}$ increased the $\mathrm{pH}$ from 4.0 to 5.82 and 5.40, respectively, and the ammonia concentration in culture filtrates to 110 and 70 $\mu \mathrm{mol} / \mathrm{liter}$, respectively. In contrast, $B$. cinerea and S. sclerotiorum cultured in similar media decreased the $\mathrm{pH}$ values to 3.75 and 3.2 and the levels of secreted ammonia reached close to 52 and $47 \mu \mathrm{mol} /$ liter, respectively, indicating no significant secretion (Fig. 8A). Similar effects were observed when $C$. gloeosporioides, F. oxysporum, B. cinerea, and S. sclerotiorum were inoculated on tomato fruit, where $\mathrm{pH}$ in the infected tissue increased from 4.2 to 4.7 and 4.9 in C. gloeosporioidesand $F$. oxysporum-inoculated fruit, respectively; whereas, in fruit inoculated with $B$. cinerea and $S$. sclerotiorum, the $\mathrm{pH}$ decreased to 3.9 and 3.8, respectively (Fig. 8B).

Sequence analysis of GDH2 and GS1 in C. gloeosporioides, $F$. oxysporum f. sp. phaseoli, B. cinerea, S. sclerotiorum, and A. niger revealed a single copy of each gene with 82 and $72 \%$ sequence identity between all the alkalinizing and acidifying species for GS1 and GDH2, respectively (Table 1). To compare the activities of glutamate and ammonium transporters in alkalinizing and acidifying strains, we searched for homologs of the GLT protein and of the highly hydrophobic AMTB ammo- nium channel of Escherichia coli (Javelle et al. 2008) in the genome sequences. The BLAST search failed to find any sequence with homology to that of the Colletotrichum GLT protein in the acidifying species. Analysis of GLT promoters in the alkalinizing species revealed several $P A C C$-binding motifs (three in Colletotrichum and four in Fusarium spp.), suggesting their expressions' high dependence on $\mathrm{pH}$ regulation and confirming the findings of Miyara and associates (2010).

A blast search of $M E P B$ versus the proteomes of the acidifying species $B$. cinerea, $S$. sclerotiorum, and $A$. niger revealed distantly related BLAST hits with e values of $3 \mathrm{e}^{-27}, 3 \mathrm{e}^{-21}$, and $2 \mathrm{e}^{-31}$, respectively, and subsequent analysis revealed that these hits are other members of the MEP family (Fig. 9). In contrast, the alkalinizing $F$. oxysporum species contained true orthologs of $M E P B$ with an e value of $3 \mathrm{e}^{-174}$. The identified sequences presented 52 to $58 \%$ similarity to the AtmB from E. coli (not shown). Three putative MEP proteins were identified in B. cinerea and $S$. sclerotiorum, whereas four putative MEP sequences were identified in $C$. gloeosporioides, $F$. oxysporum, and A. niger (Fig. 9).

Phylogenetic analysis of the MEP gene family revealed at least four distinct lineages (Fig. 9). Only lineage $C$ was conserved in all of the fungi included in this study. An ortholog of lineage A was missing from $F$. oxysporum but was otherwise
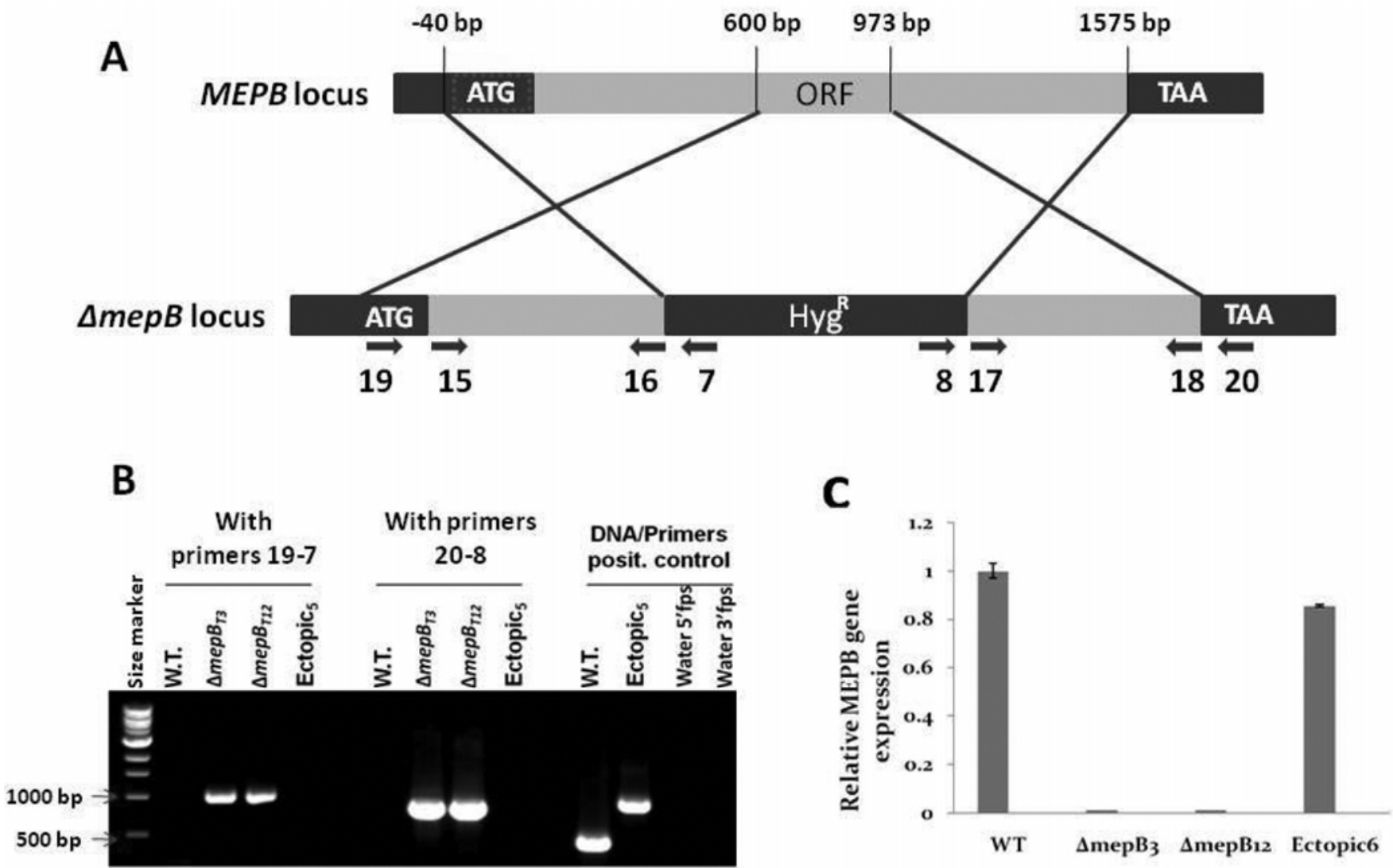

\section{C. gloeosporioides strains}

Fig. 4. Development of $M E P B$ mutant strains. A gene-replacement construct for the $M E P B$ sequence with the $M E P B 5^{\prime}-H y g$ - $M E P B 3^{\prime}$ cassette and gene recovery with $M E P B$ complementation cassette was followed. A, Scheme describing gene disruption by homologous recombination. Pairs of primers used in construct creation were 15-16 for the $5^{\prime}$ end and 17-18 for the $3^{\prime}$ end . B, Polymerase chain reaction (PCR) for identification of $M E P B$ deletion events in the wild-type (WT) strain, ectopic colony $\left(\Delta m e p B_{\text {ectopic }}\right)$, independent $M E P B$-disruption colonies $\left(\triangle m e p B^{-}\right)$, and $\Delta m e p B_{12}$ complementation colonies $\left(\Delta m e p B_{12} c^{2} p^{+}\right)$. Primer 19 flanking the position upstream of the MEPB2:HYG3 region and reverse primer 1 located on the hygromycin cassette were used to identify positive $M E P B$ gene replacement at the $5^{\prime}$ locus. Primer 2 from the hygromycin cassette and primer 20 flanking of the MEPB2:HYG3 region were used to identify MEPB gene replacement at the $3^{\prime}$ locus. $18 S$ gene primers 23 and 24 were used for WT DNA quality control. Primers 1 and 15 were used as a positive control for the ectopic 5 strains, to confirm random integration of the MEPB2:HYG3 cassette. C, Expression of MEPB in the WT strain compared with the ectopic-integration control, the $\triangle m e p B$ strains, and the $\triangle m e p B_{12}$ complementation strains, as detected by quantitative reverse-transcriptase (qRT)-PCR. Cultures were initially grown in $\mathrm{M}_{3} \mathrm{~S}$ rich medium and subsequently transferred to broth minimal medium without nitrogen source for $5 \mathrm{~h}$, prior to RNA extraction. Relative expression values obtained by qRT-PCR were normalized against $18 S$ rRNA. Average \pm standard deviation from three replications of one treatment is presented. 
conserved in both the alkalinizing and acidifying fungi. Lineage $\mathrm{B}$ was only found in the alkalinizing species whereas lineage $\mathrm{D}$ was only found in the acidifying species. This confirms our early results on the B group's specific functions in the modulation of host-tissue $\mathrm{pH}$ by the alkalinizing species. Note that additional MEP homologs were discovered in Aspergillus, Fusarium, and Colletotrichum spp. that did not belong to any of the four main lineages. Although we have tentatively assigned these additional $M E P$ genes as members of the $M E P D$ lineage, this assignment is inconclusive and a more comprehensive phylogenetic analysis is needed for a more complete understanding of the evolution of this gene family.

$M E P B$ promoter analysis in Colletotrichum and Fusarium spp. revealed several PacC-binding motifs (two in Colletotrichum and four in Fusarium spp.), suggesting their high dependence on $\mathrm{pH}$ regulation. Sequence analysis of $M E P A$ and $M E P C$ did not reveal $P A C C$-binding sites, suggesting different or more complex regulation during the alkalinization process. Thus, $M E P B$ is an ammonia transporter with no shared sequences in the acidifying species that is strongly expressed under active host colonization (Miyara et al. 2010) (Fig. 10) and represents an independent conserved group in the alkalinizing species (Fig. 9).

To analyze the transcriptional regulation of nitrogen-metabolism genes during the differential accumulation of ammonia and $\mathrm{pH}$ in culture, the transcript levels of the nitrogen-metabolism genes GDH2, MEPA (JN660155), MEPB, GLT, and GS1 were compared in culture after transfer of one representative of the alkalinizing group ( $C$. gloeosporioides) and one of the acidifying group ( $S$. sclerotiorum) to an ammonia-inducing medium. Whereas a 10 - to 90 -fold increase in the relative expression of GLT and GS1 and an up to 750-fold relative increase in $M E P B$ were observed at 12 and $48 \mathrm{~h}$ after culture inoculation with $C$. gloeosporioides (Fig. 10A), relative expression during the same period in S. sclerotiorum-inoculated media was only 2- to 3-fold higher for $G D H 2$ and less than that for the MEP genes and GS1 (Fig. 10B). These results indicated clear differential expression of the nitrogen-metabolism genes in the alkalinizing versus acidifying fungal strains under study. Under those conditions, C. gloeosporioides increased the $\mathrm{pH}$ of the medium from 4.2 to 5.7 , and the final ammonia concentration in culture filtrates reached $10^{5} \mu \mathrm{mol} / \mathrm{liter} 48 \mathrm{hpi}$ (Fig. 10C and D), whereas growth of S. sclerotiorum under the same conditions decreased the $\mathrm{pH}$ to 3.2 and final ammonia concentration reached only $40 \mu \mathrm{mol} /$ liter (Fig. 10C and D).

\section{DISCUSSION}

The ability to modulate the environment during pathogenicity, through alkalinization or acidification, has been described for several fungal pathogens (Alkan et al. 2008; Davidzon et al. 2009; Eshel et al. 2002; Hadas et al. 2007; Manteau et al. 2003; Prusky et al. 2001; Rollins and Dickman 2000). However, comparative analyses of genes contributing to pathogen colonization in the alkalinizing species or to different pathogenicity patterns are lacking. Whereas inoculation of culture and tomato fruit by $C$. gloeosporioides and $F$. oxysporum alkalinize the environment (by 1 to $2 \mathrm{pH}$ units) via the secretion of significant amounts of ammonia, S. sclerotiorum and B. cinerea acidify culture and tomato fruit by 0.5 to $1.5 \mathrm{pH}$ units. This response seems to be important for pathogenicity because it may determine the secretion of metabolites affecting the $\mathrm{pH}$ response and the consequent differential mechanism of pathogenicity for the acidifying and alkalinizing pathogens.

Previous work by Miyara and associates (2010) in C. gloeosporioides suggested the involvement of a set of nitrogenmetabolism genes in the synthesis and catabolism of ammonia.
The dynamics of ammonia accumulation suggested that acidic conditions induce $G D H 2$ production and accumulation, as well as the export of ammonia by $A M E T$. Increasing $\mathrm{pH}$ outside the fungal cells increased the expression of $M E P B$ and $G L T$ which, together with $G S 1$ activity, regulate the internal level of ammonia (Miyara et al. 2010). The $\Delta g d h 2$ mutants showed significant inhibition of ammonia accumulation and attenuation of fungal colonization (Miyara et al. 2010) but nothing was known about transporter genes regulating nitrogen metabolism that are upregulated during Colletotrichum colonization.

\section{Contribution of nitrogen metabolism to fungal colonization.}

The availability of recently published genome sequences of fungal pathogens that acidify or alkalinize the environment allowed us to carry out a genomic comparison of five fungi, three that acidify their environment (B. cinerea, S. sclerotiorum, and $A$. niger) and two that alkalinize it (C. gloeosporioides and F. oxysporum). C. gloeosporioides and S. sclerotiorum were chosen for transcriptome analysis of the genes determining the accumulation of ammonia in alkalinizing and acidifying species, respectively. Transcript analysis of the four genes modulating the alkalinization process $(G D H 2, G S 1, M E P$ genes, and $G L T$ ) revealed their 45- to 500-fold upregulation in C. gloeosporioides compared with $S$. sclerotiorum, suggesting active regulation of ammonia accumulation in Colletotrichum spp.

What is the basis for the differential expression in these two groups? GDH2 and GS1, coding for ammonia production and detoxification inside the fungal cells, were found as singlecopy genes in all five genome sequences analyzed. Pairwise sequence similarity between $C$. gloeosporioides $G D H 2$ and GS1 and their homologs in the alkalinizing and acidifying

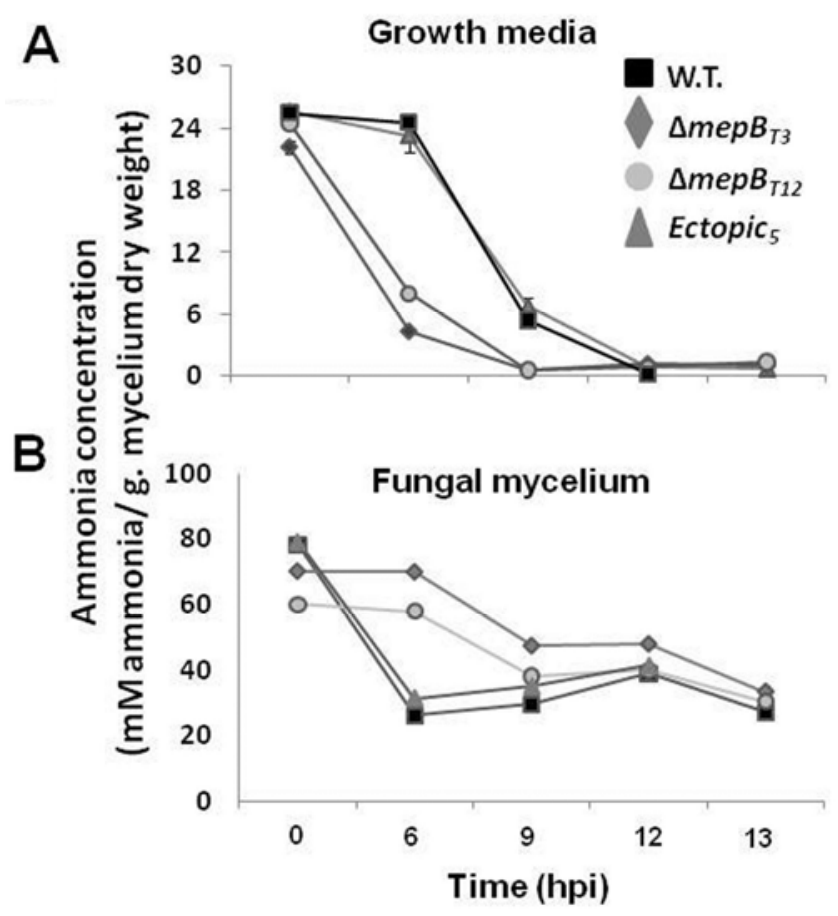

Fig. 5. Ammonia accumulation induced in the wild-type (WT) and $\triangle m e p B 2$ Colletotrichum gloeosporioides strains. A, Ammonia concentration in the culture medium. B, Ammonia concentration inside the fungal cells. Spores of $C$. gloeosporioides were inoculated in primary medium and, 3 days later, transferred to secondary medium amended with $10 \mathrm{mM}$ $\mathrm{NH}_{4} \mathrm{Cl}$, then analyzed at different hours postinoculation (hpi). Average of three replications \pm standard deviation of one experiment out of three repeated experiments is presented. 
groups ranged between 70 and $80 \%$, suggesting that the differential transcript expression in the two groups is based mainly on differential regulation of those genes. Whereas $G D H 2$ has been reported to be mainly expressed at relatively low $\mathrm{pH}$ (4 to 5) and independently of the $\mathrm{PacC}$ response, GSI is $\mathrm{pH}$ dependent and mainly expressed at pH 6 to 7 (Miyara et al. 2010). Analysis of the upstream noncoding region of GS1 revealed one GATA factor binding site and a PacC-binding motif in Colletotrichum spp. compared with none in the GS1sequence of Sclerotinia spp. However, similar analysis of the upstream promoter region of $G D H 2$ did not reveal any clear over-representation of any motif in either species and, thus, the basis for the differential expression of $G D H 2$ is still not fully understood (Schönig et al. 2008). Nevertheless, knockout of GDH2 and $A R E A$, a modulator of $G D H 2$, in $C$. coccodes reduced its ammonia secretion and pathogenicity, highlighting the importance of this nitrogen-metabolism regulation during the alkalinization process (Alkan et al. 2008; Miyara et al. 2010).

\section{Contribution of GLT and MEP transporters to fungal colonization.}

Early work, where GLT gene expression was monitored during colonization of avocado fruit by using macroarrays showed 180-fold induction (Miyara et al. 2010). In animal systems, uptake of extracellular glutamate is essential for regulating the activity of glutamate receptors, which play a role in neurological diseases (Wipf et al. 2002). However, this is the first report of a glutamate transporter in fungal systems. In silico analysis of the GLT protein showed the classical hallmarks of glutamate transport, including sodium binding, potassium coupling, and glutamate $\gamma$-carboxylate-binding sites, suggesting an active glutamate transporter (Fig. 1). The C. gloeosporioides GLT sequence showed similarity to a hypothetical protein and to an unidentified amino acid transporter in F. oxysporum, with $70 \%$ identity, whereas no homologs were found in any of the acidifying fungal species. Functional analysis of $\Delta g l t$ strains indicated that GLT contributes to appressorium formation and to pericarp colonization by $C$. gloeosporioides following growth under reduced nitrogen conditions. Miyara and associates (2010) reported that glutamate uptake led to the production of ammonia by activation of $G D H 2$ or by inducing $G S$ and the production of glutamine and, from that, to amino acids that may be catabolized to ammonia (Fig. 11). In the present results, only after three transfers of the $\Delta g l t$ strains on reduced $\mathrm{KNO}_{3}$ media, when the internal glutamate pools have probably declined, was a different phenotypic response of the $\Delta g l t$ strains from that of the WT observed. This suggests that the GLT transporter contributes to nitrogen metabolism via uptake of available glutamate during early biotrophic stages, when few nitrogen sources are available; whereas, during the necrotrophic stage, when amino acids are abundant, other types of transporters such as MEPB contribute to the import of nitrogen material.

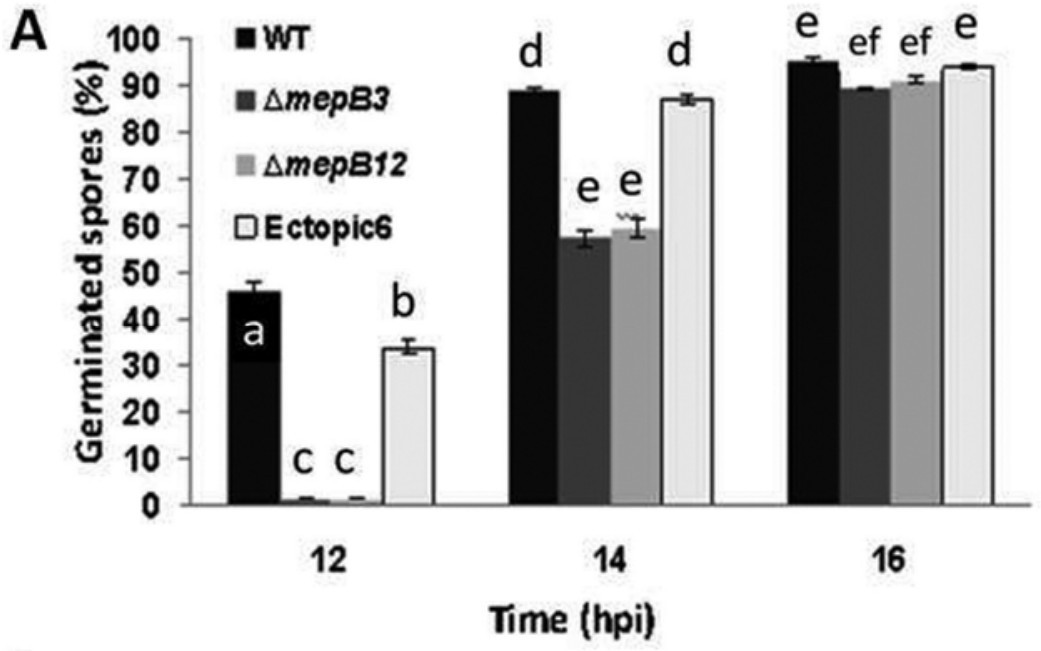

B

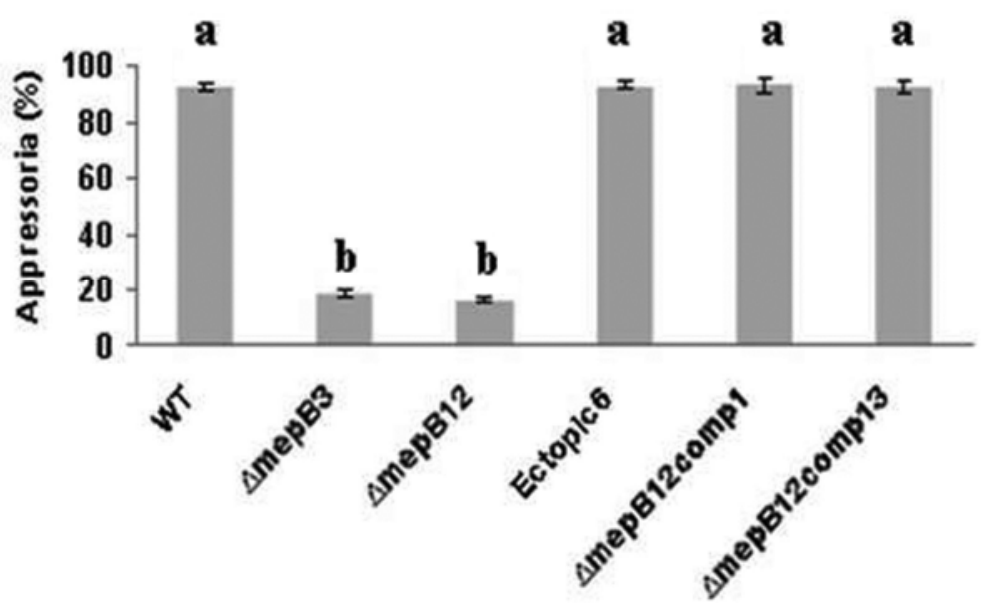

Fig. 6. Comparisons of $\mathbf{A}$, spore germination and $\mathbf{B}$, appressoria formation induced in the wild-type (WT) and $\Delta m e$ pB2 Colletotrichum gloeosporioides strains. Germination of the WT, $\triangle m e p B 2$, and ectopic strains was evaluated at particular times (hours postinoculation [hpi]). Appressoria formation was evaluated 12 to 14 hpi and was compared to the complemented strains. The averages of three replications \pm standard deviation are presented. Values within columns marked with different letters differ significantly according to Tukey-Kramer's highly significant differences test at $P \leq 0.05$. 
An explanation for the absence of GLT-homologous sequences in acidifying species might be based on the analysis of the GLT transporters from Streptococcus pneumoniae, in which downregulation of gene expression and reduced activity of GLT occur under low acidic $\mathrm{pH}$ conditions (Krastel et al. 2010). S. mutans also shows decreased activity of amino acid transporters under acidic conditions, whereas their activities increase at $\mathrm{pH} 6.0$ (Sato et al. 1989). A similar response has been reported for $C$. gloeosporioides, with GLT strongly expressed mainly under alkaline conditions, and was confirmed by analysis of the upstream regions of the coding sequences in the alkalinizing species which showed several PACC motifs (Miyara et al. 2010).

It might also be that some sequences in the acidifying species have diverged too extensively from the alkalinizing group to be recognized as homologs. For example, differences in the number of transporters between groups might suggest systematic gene loss and genome compaction as possible factors reducing the number of transport proteins in the acidifying species (Hong 1998; Linton and Higgins 1998; Nakanishi and Masu 1994; Tolner et al. 1955; Zientz et al. 2004). The observation of differential function in the $\Delta g l t$ strains only following growth under low nitrogen conditions suggests that GLT function might be critical during the pathogen's long periods as ungerminated or quiescent germinated spores on host fruit (Prusky 1996).

The most significant contribution to alkaline fungal colonization, as well to the differences between the acidifiers and alkalinizers, was found to be the differential transcript expression of $M E P$ genes and the specific sequence of MEPB, as determined by phylogenetic analysis of the $M E P$ family. Miyara and associates (2010) suggested that $M E P B$ is involved in nitrogen metabolism occurring during pathogenicity of $C$. gloeosporioides in fruit. Sequence analysis determined the presence of a well-conserved family of three ammonium transporters that has been characterized in most reported fungi (Teichert et al. 2008). However, the differential localization of $M E P B$ within the alkalinizing species indicates a specific sequence not present in the acidifying fungal group.

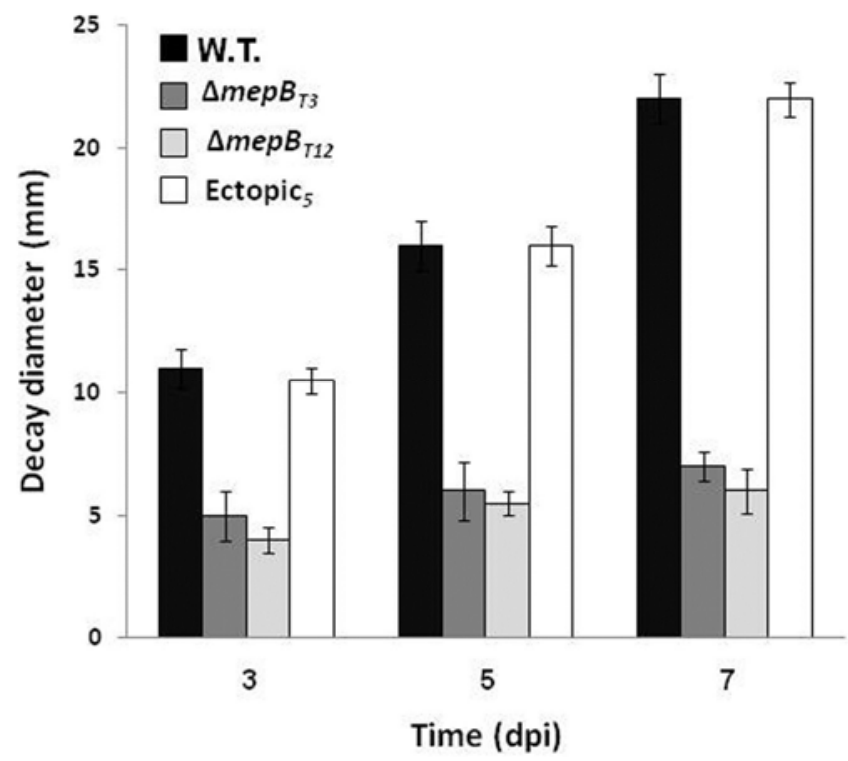

Fig. 7. Pathogenicity assays of Colletotrichum gloeosporioides wild-type (WT) and $\triangle m e p B$ mutant strains. Decay development of WT and mutant strains after inoculation of peeled freshly harvested avocado fruit. Average colonized area \pm standard deviation for 10 infected fruit 3, 5, and 7 days postinoculation (dpi) is reported. Inoculation was carried out on a 1-mmdeep, 5-mm-diameter wound in the fruit mesocarp of peeled fruit followed by incubation at $25^{\circ} \mathrm{C}$ under high humidity.
The MEP proteins scavenge ammonia from the medium to be used as a nitrogen source (Rutherford et al. 2008; Teichert et al. 2008) and are abundantly expressed under the alkaline conditions induced by C. gloeosporioides (Miyara et al. 2010). The $\triangle m e p B$ mutant strain showed rapid uptake of ammonia from the medium and accumulation of ammonia inside the mycelium compared with the WT and complemented mutants. This may suggest that $M E P B$ regulates not only the import but also the export of ammonia. A possible bidirectional diffusion of ammonium was reported for $A M T B$ transporters (homolog of $M E P B$ ) of Saccharomyces cerevisiae (Soupene et al. 2001). The reduced ammonia secretion by these $\triangle m e p B$ mutants explains their reduced pathogenicity when inoculated on avocado fruit (Alkan et al. 2008, 2012). Considering its expression pattern in Colletotrichum spp., this transporter may represent a key component in the mechanisms that mediate and regulate ammonia production and secretion in alkalinizing species.

It is still not known whether $M E P B$ is the main or only regulator of ammonia import and export. Protein analysis of MEPB showed the remarkable conservation of the histidine pore (at amino acid 168) (Javelle et al. 2006, 2008) and this suggests a role in allowing the substrate to cross the central part of the channel (Andrade et al. 2005; Khademi et al. 2004; Winkler 2006; Zheng et al. 2004). The transporter's precise function (i.e., serving as a proton acceptor for the entering ammonium

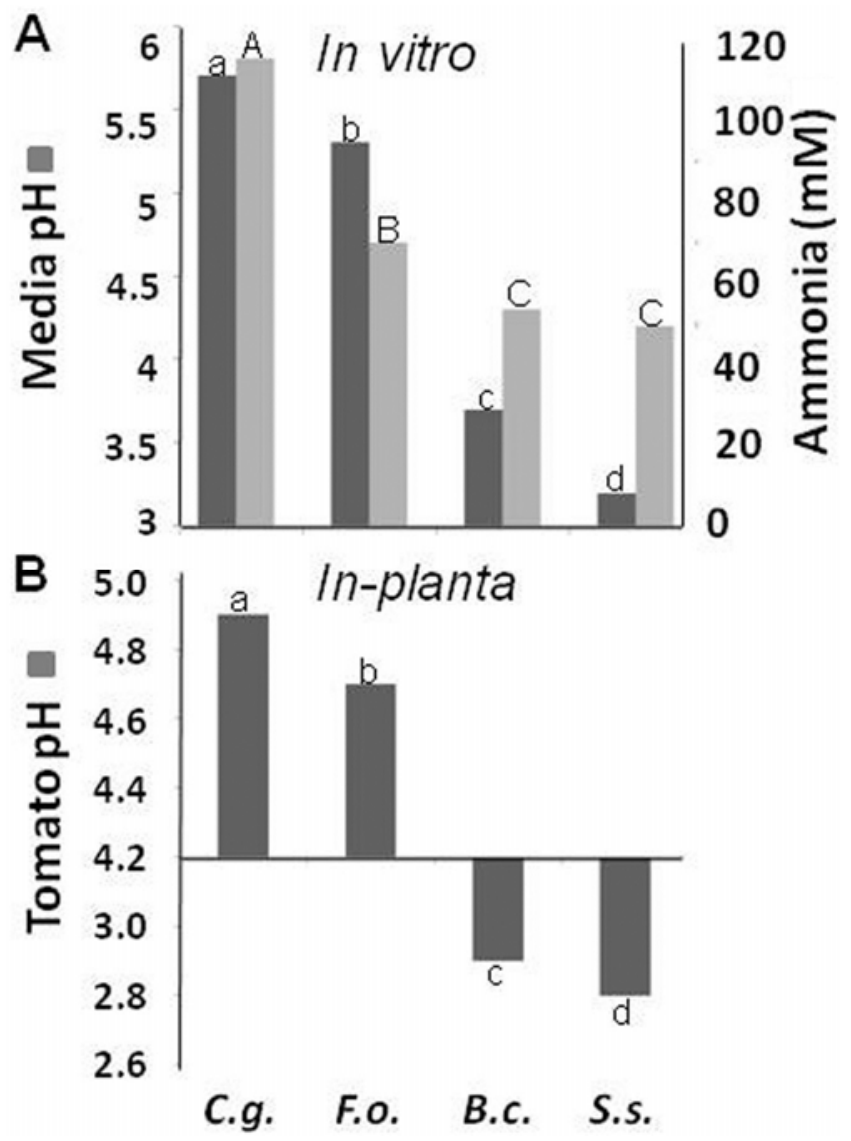

Fig. 8. Ammonia accumulation and $\mathrm{pH}$ changes induced by Colletotrichum gloeosporioides, Fusarium oxysporum, Botrytis cinerea, and Sclerotinia sclerotiorum. A, In vitro: inducing medium amended with $\mathrm{KNO}_{3}$ was inoculated with $10^{6}$ spores per $40 \mathrm{ml}$ in a $100-\mathrm{ml}$ vial, and $\mathrm{pH}$ and ammonia concentrations were determined $48 \mathrm{~h}$ later. B, In planta: a wounded tomato fruit was inoculated with a $10-\mu 1$ drop $\left(10^{5} \mathrm{~s}\right.$ pores $)$ and incubated at $20^{\circ} \mathrm{C}$, and measurements were taken 4 to 5 days later. Values within columns marked with different letters (capitals and lowercase) differ significantly according to Tukey-Kramer's honestly significant difference test at $P \leq 0.05$. 
ion or, more simply, shaping the pore and balancing its polarity) remains to be determined. Interestingly, in MEPC, His 168 is changed to a glutamic acid (E). Javelle and associates (2006) demonstrated that the H168E point mutation does not affect the transporter's overall structure but reduces its activity by approximately $25 \%$ compared with WT proteins. This might imply that all fungal MEP C transporters have reduced activity compared with the proteins with a His168 pore, suggesting that MEPB might actually present different biochemical properties compared with other, less active MEP proteins, such as MEPC and MEPD, and this may further contribute to the differential expression in acidic and alkaline species.

Alkalinization of host tissue by enhanced nitrogen metabolism during necrotrophic growth is a major factor in the development of Colletotrichum spp. in different hosts. The present work demonstrated that Fusarium spp. also use ammonium secretion as a novel strategy for fungal colonization of different hosts. Ammonia's mechanism of action includes optimization of the $\mathrm{pH}$ of the infection court for activation of fungal virulence genes, and simultaneous activation of the host respiratory burst oxidase homolog which appears to stimulate salicylic acid pathway responses and suppress jasmonic acid pathway responses (Alkan et al. 2012). These processes correlate with local cell death and enhance the aggressiveness of the pathogen in its necrotrophic stage. Taken together, the differences that activate pathogenicity in the alkalinizing species include i) differential transcript expression of genes modulating ammonia accumulation; ii) presence of the GLT transporter, which modulates appressorium formation and pathogenicity; and iii) presence of specific permease $M E P B$ that modulates ammonia import or accumulation and pathogenicity. However, it is still unclear how the genes that determine ammonia accumulation are regulated. Functional analysis of the loss-of-function $\Delta p a c 1$, which reduces pathogenicity of the alkalinizing $C$. gloeosporioides, revealed downregulation of $G S 1, G L T$, and $M E P B$ expression (Miyara et al. 2010). This behavior was confirmed by the detection of consensus sequences of $P A C C$ in the promoter regions of $G L T$ and $M E P B$ in all of the alkalinizing species. However, analysis of the upstream untranslated regions of $G D H 2$ and GS1 in the alkalinizing species showed few AREA and PACC motifs, suggesting a different modulating mechanism there. This differential expression pattern within the alkalinizing fungal species suggests that the classical transcription factors are not the only ones modulating the differential expression of genes in acidifying and alkalinizing species.

\section{MATERIALS AND METHODS}

\section{Fungal isolates, media, and growth conditions.}

Single-spore cultures of the WT Cg-14 isolate of C. gloeosporioides, obtained from a decayed avocado fruit (Persea americana 'Fuerte') in Israel, and all of the $C$. gloeosporioides $M E P B$ mutant strains used in this work were routinely cultured on $\mathrm{M}_{3} \mathrm{~S}$ agar as described by Miyara and associates (2010). Cultures were supplied as follows: $F$. oxysporum (FOX Sp4) by J. M. Minguez (University of Salamanca, Spain), B. cinerea by L. Benito (University of Salamanca), and Sclerotinia sclerotiorum by M. Dickman (Texas A\&M, College Station, TX, U.S.A.), and were grown on potato dextrose agar. $\mathrm{M}_{3} \mathrm{~S}$ medium (primary medium), used for the initial growth of the fun-

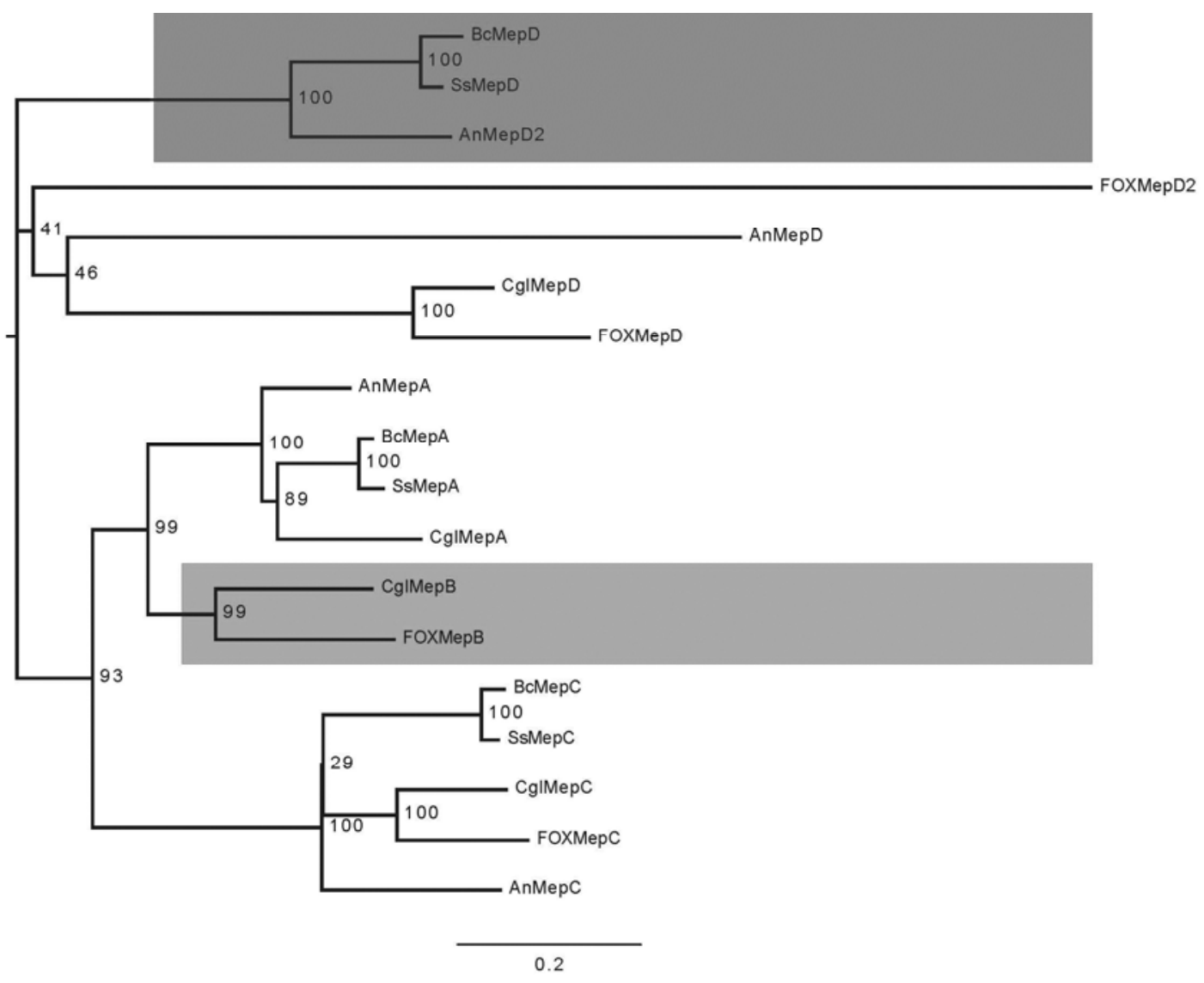

Fig. 9. Phylogenetic analysis of the $M E P$ gene family. Phylogenetic reconstruction was performed using PHYML and evaluated using a bootstrap test with 100 replications. Numbers on branches are bootstrap support values. The $M E P B$ clade, found only in alkalinizing species, is highlighted in light gray. The MEPD clade, found only in acidifying species, is highlighted in dark gray. Species codes: Colletotrichum gloeosporioides (Cg), Fusarium oxysporum f. sp. phaseoli (FOX), Aspergillus nidulans (An), Sclerotinia sclerotiorum (Ss), and Botrytis cinerea $(\mathrm{Bc})$. 
gus prior to exposing it to different nutritional induction factors (Miyara et al. 2010), contained (per liter) $2.5 \mathrm{~g}$ of $\mathrm{MgSO}_{4}$. $7 \mathrm{H}_{2} \mathrm{O}, 2.7 \mathrm{~g}$ of $\mathrm{KH}_{2} \mathrm{PO}_{4}, 1.0 \mathrm{~g}$ of Bacto peptone, $1.0 \mathrm{~g}$ of Bacto yeast extract (Difco Laboratories, Detroit), $10 \mathrm{~g}$ of sucrose, and $250 \mathrm{mg}$ of chloramphenicol. The cultures were incubated at 22 to $24^{\circ} \mathrm{C}$ in a shaking incubator at $150 \mathrm{rpm}$ for 3 days and were harvested by filtration through a sterile Büchner funnel fitted with filter paper. The hyphal mat was washed twice with $40 \mathrm{ml}$ of sterile distilled water. The washed mycelia were resuspended in $40 \mathrm{ml}$ of fresh SM containing (per liter): $4 \mathrm{~g}$ of $\mathrm{KH}_{2} \mathrm{PO}_{4}, 2 \mathrm{~g}$ of $\mathrm{MgSO}_{4} \cdot 7 \mathrm{H}_{2} \mathrm{O}, 0.3 \mathrm{~g}$ of $\mathrm{CaCl}_{2} \cdot 2 \mathrm{H}_{2} \mathrm{O}, 10 \mathrm{mg}$ of $\mathrm{FeCl}_{3}, 50 \mathrm{mM}$ glucose, and $1.0 \mathrm{~g}$ of $\mathrm{KNO}_{3}$. When $\mathrm{Fu}$ sarium, Botrytis, or Colletotrichum spp. were compared for ammonia secretion, spore suspensions $\left(10^{6}\right.$ spores per $40 \mathrm{ml}$ in a $100-\mathrm{ml}$ vial) were inoculated into inducing media. Inoculation of S. sclerotiorum for similar evaluations was performed with 10 plugs of $5 \mathrm{~mm}$ in diameter, sampled from the leading edge of a developing colony. The initial $\mathrm{pH}$ for each flask was determined after the medium had been autoclaved but prior to inoculation. The experiments were repeated at least three times, and the results of a single representative experiment are shown. Differences between experiments in the average values for each treatment did not exceed 2 to $3 \%$.

\section{Fruit inoculation and appressorium formation.}

Freshly harvested tomato fruit from a local supermarket were used for inoculation. Spores of C. gloeosporioides, F. oxy- sporum, and B. cinerea strains were inoculated on the mesocarp of tomato fruit by peel-wounding the fruit with a nail and placing $10 \mu \mathrm{l}$ of a conidial suspension $\left(10^{6}\right.$ conidia $\left./ \mathrm{ml}\right)$ on each of three equally spaced inoculation spots. For inoculation of S. sclerotiorum, three 5-mm-diameter agar plugs from the leading edge of a developing colony were used. Each fungal inoculum was placed on the equatorial circle of five different fruit per treatment (i.e., 15 inoculation replicates per fungal strain per experiment).

In some experiments, $C$. gloeosporioides was inoculated on Fuerte avocado fruit freshly harvested from an orchard in Israel. Spores of the various $C$. gloeosporioides strains were inoculated on the avocado fruit peel by placing $7 \mu \mathrm{l}$ of a conidial suspension $\left(10^{6}\right.$ conidia/ml $)$ on each of three longitudinally spaced inoculation spots on each side of 10 different fruit per treatment (i.e., 60 inoculation replicates per treatment). When fruit were inoculated on the mesocarp, a 1- to 2-mm strip of peel tissue was removed from the fruit and $7 \mu \mathrm{l}$ of a conidial suspension $\left(10^{6}\right.$ conidia/ml $)$ was placed into 1-mm-deep, 1-mmdiameter inoculation spots in the fruit mesocarp. Five inoculation spots, longitudinally spaced, on each side of 10 different fruit were inoculated per treatment. The inoculation experiments were repeated three times and one representative experiment is presented.

For appressorium formation and maturation-detection experiments, Colletotrichum WT and mutant isolates were observed on glass slides. Briefly, 5 to $25 \mu \mathrm{l}$ of a conidial suspension $\left(10^{6}\right.$

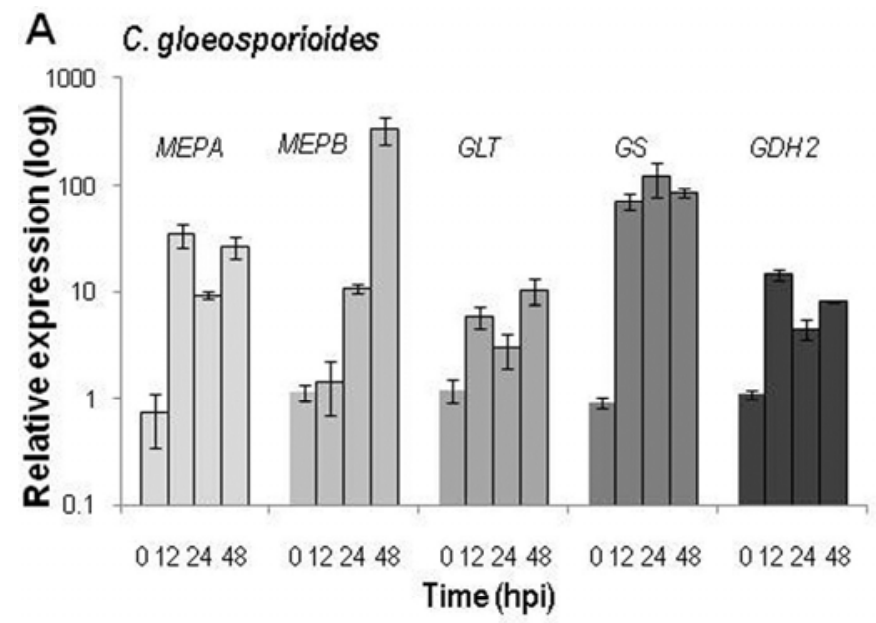

\section{B S. sclerotiorum}

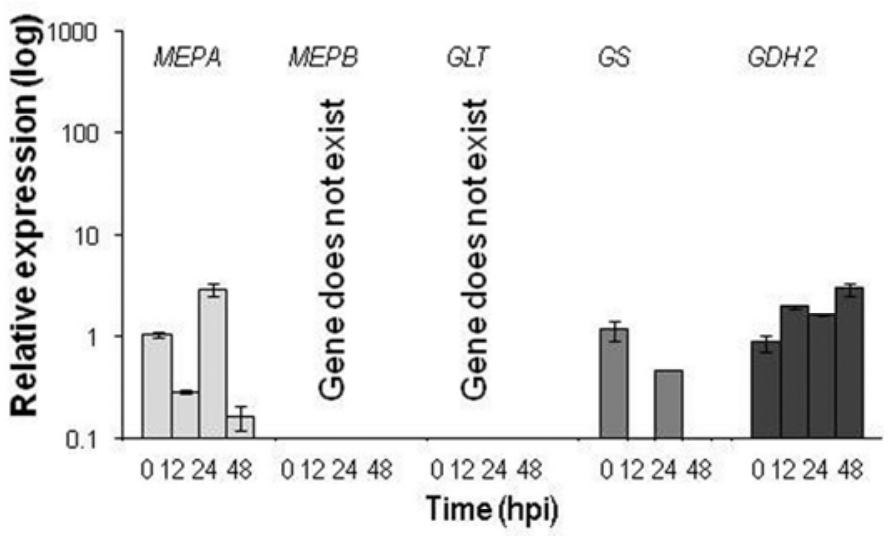

C

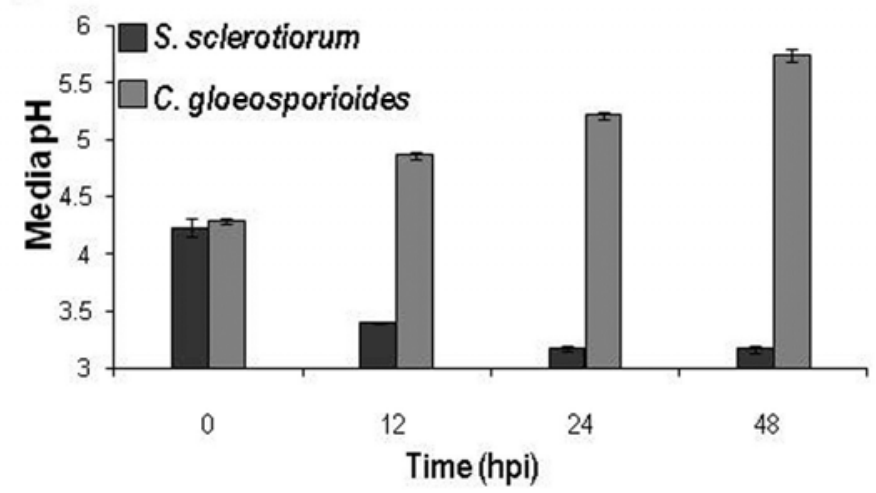

D

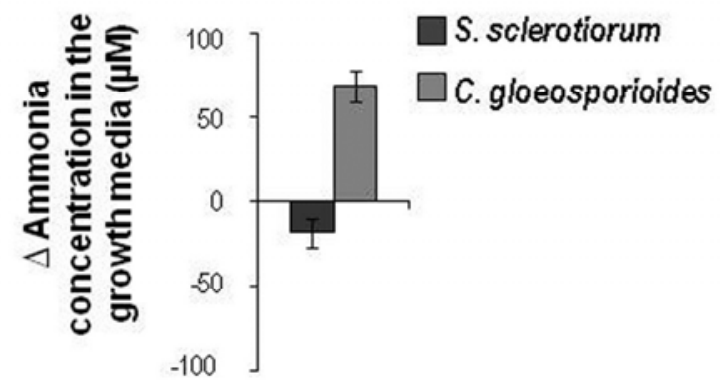

Time (48 hpi)

Fig. 10. Comparison of $\mathrm{pH}$ change, ammonia secretion, and relative expression of GDH2, MEP genes, GS1, and GLT in alkalinizing Colletotrichum gloeosporioides and acidifying Sclerotinia sclerotiorum during growth on $\mathrm{KNO}_{3}$ ammonia-inducing medium. A and $\mathbf{B}$, Relative expression of GDH2, MEPA, $M E P B, M E P C, G L T$, and $G S 1$ in C. gloeosporioides and S. sclerotiorum, respectively. C, Induced $\mathrm{pH}$ changes. D, Ammonia $\Delta_{\mathrm{NH} 3}$ (final-initial concentration). Samples were collected at various hours postinoculation (hpi) to perform the different assays. Initial ammonia concentration in the media was 35 $\mu \mathrm{mol} /$ liter. Relative expression of the genes was compared with that of the constitutive $18 \mathrm{~S}$ ribosomal gene. Average of three replications \pm standard deviation is presented. 
conidia/ml) of each isolate was placed on five glass slides and kept on moistened filter paper in a moist chamber. After 12 to $14 \mathrm{~h}$ of incubation, conidial germination and appressorium development were observed in three microscopic fields in each of five cells per slide. Maturation of appressoria was defined according to melanization level: mature appressoria were considered to be only those that were fully melanized compared with hyaline-less pigmented ones, which were considered immature.

\section{pH measurement and ammonia detection.}

$\mathrm{pH}$ was measured in $0.5-\mathrm{ml}$ aliquots of the culture media collected at various times after fungal inoculation using a Thermo-Orion Model 9810BN microcombination $\mathrm{pH}$ electrode (Thermo Fisher Scientific, Inc., Waltham, MA, U.S.A.). Ammonia was detected colorimetrically with an ammonium test kit (Merck, Darmstadt, Germany). The concentration of ammonia was determined in $5 \mathrm{ml}$ of 10-fold-diluted culture supernatants according to the manufacturer's instructions. Briefly, the sample containing ammonium was adjusted to $\mathrm{pH} 13$ so that the ammonium was transformed to ammonia, which could then be detected colorimetrically at $690 \mathrm{~nm}$. Concentrations were reported in millimolar ammonia. For determination of ammonia concentration inside the fungal cells, $100 \mathrm{mg}$ of freshly collected mycelium was homogenized and then centrifuged at $10,500 \times g$ for $5 \mathrm{~min} ; 50 \mu \mathrm{l}$ of the supernatant was diluted to
$5 \mathrm{ml}$ and ammonium was detected colorimetrically with the ammonium test kit.

\section{RNA extraction and qRT-PCR analysis.}

RNA for real-time qRT-PCR analysis was extracted from 80 mg (dry weight) of mycelium with RNeasy plant mini kit (Qiagen Sciences, Hilden, Germany) and further purified by treatment with a TURBO DNA Free kit (Ambion, Austin, TX, U.S.A.). The reverse-transcription reaction was performed on $1 \mu \mathrm{g}$ of total RNA with the Reverse-It first-strand synthesis kit (ABgene, Surrey, U.K.). Samples of cDNA were diluted 1:10 ( $\mathrm{vol} / \mathrm{vol})$ to the final template concentration for qRT-PCR. Real-time qRT-PCR was performed with a RotorGene 3000 system (Corbett Research, Sydney, Australia). PCR amplification was run using $3.5 \mu \mathrm{l}$ of cDNA template in $10 \mu \mathrm{l}$ of a reaction mixture containing $5 \mu \mathrm{l}$ Syber-Green amplification kit (ABgene) and $300 \mathrm{nM}$ primers. PCR conditions were initial denaturation for $15 \mathrm{~min}$ at $94^{\circ} \mathrm{C}$; 40 denaturation cycles of $10 \mathrm{~s}$ at $94^{\circ} \mathrm{C}$; annealing at $60^{\circ} \mathrm{C}$ for $15 \mathrm{~s}$; extension at $72^{\circ} \mathrm{C}$ for $20 \mathrm{~s}$ (cycling A), $77^{\circ} \mathrm{C}$ for $6 \mathrm{~s}$ (cycling B), and $80^{\circ} \mathrm{C}$ for $6 \mathrm{~s}$ (cycling $\mathrm{C}$ ); and melting at 72 to $99^{\circ} \mathrm{C}$. The samples were subjected to melting-curve analysis with the RotorGene program. All samples were normalized to $18 \mathrm{~S}$ rRNA gene levels in the same qRT-PCR, and the values were expressed as increase or decrease in levels relative to a calibration sample. The forward and reverse primers for all of the genes are given in Supple-

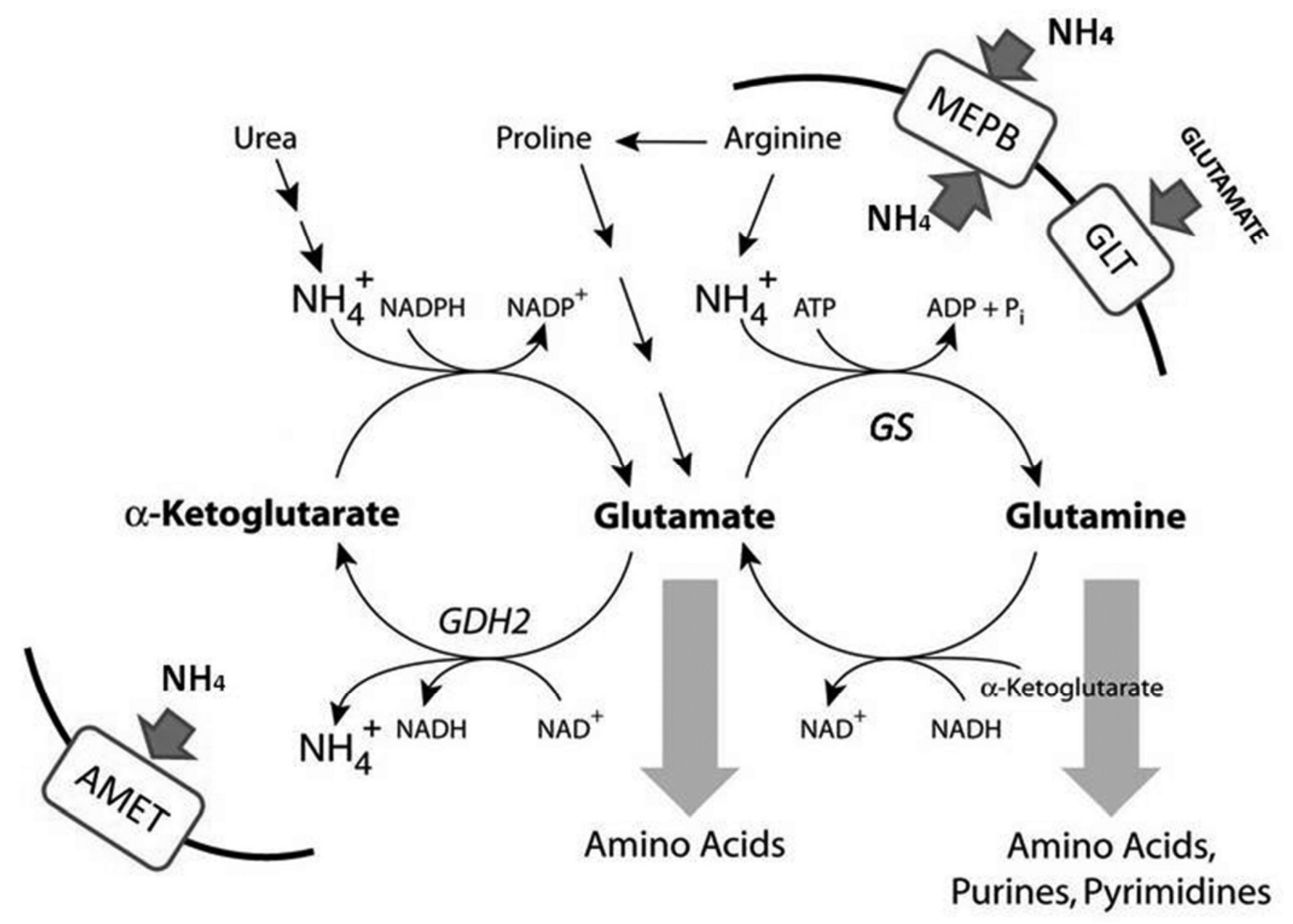

Fig. 11. Central pathways for nitrogen metabolism. Nitrogenous compounds in the cell are synthesized from either glutamate or glutamine. The major pathway for glutamate synthesis is through combination of ammonia with $\alpha$-ketoglutarate, which is synthesized from acetyl CoA and oxaloacetate through the early steps of the citric acid cycle. Glutamine is synthesized by the combination of ammonia with glutamate. Pathways for utilization of a variety of nitrogen sources, including urea, proline, and arginine, are shown. The production of ammonia by Colletotrichum gloeosporioides is by the activation of GDH2. The presence of the MEPB and GLT transporters are shown (adapted from Magasanik and Kaiser 2002). 
mentary Table S1. Each experiment was repeated at least three times with similar results, and the results of one experiment are presented.

\section{Creation of $C$. gloeosporioides GLT and MEPB mutants.}

Generation of knockout construct. The $5^{\prime}$ and $3^{\prime}$ flanking fragments of the coding region of $C$. gloeosporioides $M E P B /$ $G L T$ were amplified by PCR from the full gene deposited in GenBank. For $M E P B$, primer sets $15-16$ and $17-18$ were used to amplify the $5^{\prime}$ and $3^{\prime}$ fragments, respectively. For $G L T$, the primer sets 33-34 and 35-36 were used to amplify the $5^{\prime}$ and $3^{\prime}$ fragments, respectively. PCR tests included (in $25 \mu \mathrm{l}$ of reaction volume) $30 \mathrm{ng}$ of DNA, 10 pmol oligonucleotide primers, $12.5 \mathrm{mM}$ dNTPs, $1 \mu \mathrm{l}$ of Taq polymerase in $10 \times$ PCR buffer, and double-distilled water. The construct was generated through GATEWAY technology according to the manufacturer's instructions (Shafran et al. 2008). The plasmid was isolated, sequenced, and digested with NotI to release the deletion construct.

Electroporation of germinating conidia was performed essentially as previously described (Horowitz et al. 2002; Yakoby et al. 2001). Briefly, Cg-14 isolates were cultured on solid $\mathrm{M}_{3} \mathrm{~S}$ medium for 14 days. Conidia were collected in pea juice (Robinson and Sharon 1999), adjusted to $10^{6}$ conidia/ml, and incubated at $28^{\circ} \mathrm{C}$ for 2 to $3 \mathrm{~h}$ to initiate germination. The germinated conidia were collected, washed with cold electroporation buffer (1 $\mathrm{mM} \mathrm{n}$-2-hydroxyethylpiperazine-N-2-ethenesulfonic acid, and $50 \mathrm{mM}$ mannitol, $\mathrm{pH}$ 7.5), and concentrated to $10^{8}$ conidia/ml, and $100-\mu \mathrm{l}$ aliquots were distributed in cold electroporation cuvettes (Bio-Rad, Hercules, CA, U.S.A.). Electroporation and transfer to regeneration medium were performed according to Shafran and associates (2008). Transgenic colonies appeared 3 to 4 days after transformation. The transformants were regrown as single colonies on $\mathrm{M}_{3} \mathrm{~S}$ agar with hygromycin B at $80 \mathrm{mg} / \mathrm{liter}$, and DNA was extracted with the Master Pure yeast purification kit (Epicentre Biotechnologies, Madison, WI, U.S.A.).

Gene deletion analysis. GLT gene-disruption events were first analyzed by PCR screening for integration of the GLT5' Hyg-GLT3' cassette at the GLT locus (Fig. 5A and C). For that purpose, primer pairs 1-35 and 2-36 were designed on the basis of the region flanking the disruption cassette at the $5^{\prime}$ and $3^{\prime}$ ends of the Hyg cassette (Fig. 5A and C), respectively. Primer set 1-33 was designed to analyze ectopic integration strains (Fig. 6A). In the case of homologous integration, 1,995- and 900-bp amplicons from the 5' and $3^{\prime}$ region, respectively, were observed in transformants $\Delta g t_{5}, \Delta g t_{6}$, and $\Delta g t_{31}$, indicating integration of the disruption cassette into the GLT locus (Fig. 6A). In the case of ectopic integration, an 830-bp amplicon was observed (Fig. 5A). The $18 S$ ribosomal gene was used for WT DNA quality control resulting in a 150-bp amplicon (Fig. 5A). All PCR fragments were sequenced for verification. Gene expression of GLT by qRT-PCR (Fig. 5B) was detected in WT progenitor Cg-14 and ectopic ${ }_{10}$ strains but not in $\Delta g t_{5}, \Delta g l t_{6}$, and $\Delta g l t_{31}$ strains, confirming the functionality of the disruption.

Gene-disruption events for $M E P B$ were first analyzed by PCR screening for integration of the MEPB5'-Hyg-MEPB3' cassette at the MEPB locus (Fig. 8A and C). Primer pairs 1-19 and 2-20 were designed on the basis of the region flanking the disruption cassette at the $5^{\prime}$ and $3^{\prime}$ ends on the Hyg cassette (Fig. 8A and C), respectively. Primer set $1-15$ was designed to analyze ectopic integration strains (Fig. 8A). In the case of homologous integration, 990- and 750-bp amplicons from the $5^{\prime}$ and $3^{\prime}$ regions, respectively, were observed in transformants $\triangle m e p B_{3}$ and $\triangle m e p B_{12}$, indicating integration of the disruption cassette into the $M E P B$ locus (Fig. 8A). In the case of ectopic integration, an 890-bp amplicon was observed (Fig. 8A). An $18 S$ ribosomal gene was used for WT DNA quality control, resulting in a 150-bp amplicon (Fig. 8A). All PCR fragments were sequenced for verification. Gene expression of $M E P B$ by qRT-PCR (Fig. 8B) was detected in WT progenitor Cg-14 and

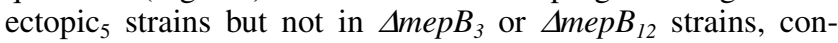
firming the functionality of the disruption.

Generation of complementation construct. Transformant $\triangle m e p B_{12}$, a representative $M E P B$ gene-replacement strain, was utilized as a recipient for complementation via transformation with the pDEST-Phleo vector, which contains the intact genomic $M E P B$, including 1,000 bp of native promoter and 300 bp of native terminator (accession number GH270299) and a marker conferring resistance to phleomycin. Resistant transformants were recovered, and three strains were analyzed by PCR using primer pairs 3-22 and 4-21, with primers 21 and 22 designed on the basis of the regions on the phleomycin cassette. In the case of positive integration, a 1,000-bp amplicon was observed in transformants $\Delta m e p B_{12}$ comp $_{1,13}$, indicating integration of the complementation cassette into strain $\Delta m e p B_{12}$ (Fig. 4A and D).

Genomic DNA extraction. Fungal cells were inoculated into liquid $\mathrm{M}_{3} \mathrm{~S}$ for 3 to 5 days at $28^{\circ} \mathrm{C}$. For PCR analysis, $50 \mathrm{mg}$ of wet tissue was used following the protocol of the Master Pure kit (Epicentre Biotechnologies). For Southern analysis, genomic DNA was prepared following the protocol of Möller and associates (1992) using $0.5 \mathrm{~g}$ of wet tissue.

\section{Genome sequence and phylogenetic analysis.}

A draft genome sequence of $C$. gloeosporioides was obtained by sequencing total genomic DNA to a depth of approximately $8 \times$ using the Roche 454 Titanium platform. Gene models were annotated using GeneMark (Ter-Hovhannisyan et al. 2008) and all of the genes used in this analysis were deposited in GenBank. Other sequenced genomes are publicly available from the National Center for Biotechnology Information.

The phylogenetic tree of the $M E P$ gene family was constructed with PHYML software (Guindon and Gascuel 2003) using the JTT model and optimized for tree topology, branch length, and rate of evolution. Tree support was evaluated using a bootstrap test with 100 replications.

\section{Accession numbers.}

Sequence data from this study of each gene and its promoter from C. gloeosporioides can be found in the EMBL and GenBank data libraries under the following accession numbers: GLT, JN660151; GDH2, JN660152; GS1, JN660153; MEPA, JN660155; $M E P B$, JN660156; $M E P C$, JN660157; and $M E P D$, JN660154. The accession numbers for the GDH2 genes are Magnaporthe, XP_399530; Fusarium, EUG76650.1; Sclerotinia, SS1G_00002; Botrytis, BC1G_15454.1; and Aspergillus, An02g14590. The accession numbers for other genes were obtained from the Broad Institute published database. The accession numbers for the GS1 genes are Magnaporthe, XP_001402868; Fusarium, FOXG_05182; Sclerotinia, XP_ 001588876; Botrytis, BC1G_12011; and Aspergillus, An01g08800. The accession numbers for the GLT genes are $\mathrm{Fu}$ sarium, FOXG_03264.2 and Magnaporthe, XP 367728.1. The accession numbers for the $M E P$ genes, other than of Colletotrichum, are as follows. A. niger: AnMEPA XP_001392437, AnMEPC XP_001400572, AnMEPD XP_001389574, and AnMEPD2 XP_001400856; B. cinerea: BcMEPA CCD52297, BcMEPC CCD45586, BcMEPD CCD34682; F. oxysporum: FOXMEPB EGU79127, FOXMEPC EGU78832, FOXMEPD EGU75233, FOXMEPD2 EGU81805; and S. sclerotiorum: SsMEPA XP_001592360, SsMEPC XP_001594694, and SsMEPD XP_001593457. 


\section{ACKNOWLEDGMENTS}

This research was supported, in part, by research grant number IS3945-06 from BARD, the United States-Israel Binational Agricultural Research and Development Fund. Part of the genome sequencing of C. gloeosporioides was funded by BARD projects. We thank L. Benito, University of Salamanca, Spain, for supplying Botrytis MEP sequences.

\section{LITERATURE CITED}

Alkan, N., Fluhr, R., Sherman, A., and Prusky, D. 2008. Role of ammonia secretion and $\mathrm{pH}$ modulation on pathogenicity of Colletotrichum coccodes on tomato fruit. Mol. Plant-Microbe Interact. 21:1058-1066.

Alkan, N., Davydov, O., Sagi, M., Fluhr, R., and Prusky, D. 2009. Ammonium secretion by Colletotrichum coccodes activates host NADPH oxidase activity enhancing host cell death and fungal virulence in tomato fruits. Mol. Plant-Microbe Interact. 22:1484-1491.

Alkan, N., Fluhr, R., and Prusky, D. 2012. Colletotrichum coccodes infection of ripe and unripe tomato fruit is modulated by ammonium secretion through salicylic and jasmonic acid pathways leading to PCD and differential colonization. Mol. Plant-Microbe Interact. 25:85-96.

Andrade, S. L., Dickmanns, A., Ficner, R., and Einsle, O. 2005. Crystal structure of the archaeal ammonium transporter Amt-1 from Archaeoglobus fulgidus. Proc. Natl. Acad. Sci. U.S.A. 102:14994-14999.

Davidzon, M., Kobiler, I., Alkan, N., and Prusky, D. 2009. Acidification of fruit environment by gluconic acid during decay development of Phomopsis mangiferae. Postharvest Biol. Technol. 55:71-77.

Dickman, M. 2007. Approaches for crop improvement to soilborne fungal diseases through biotechnology: Sclerotinia sclerotiorum as a case study. Aust. Plant Pathol. 36:116-123.

Diéguez-Uribeondo, J., Förster, H., and Adaskaveg, J. E. 2008. Visualization of localized pathogen-induced $\mathrm{pH}$ modulation in almond tissues infected by Colletotrichum acutatum using confocal scanning laser microscopy. Phytopathology 98:1171-1178.

Drori, N., Kramer-Haimovich, H., Rollins, J., Dinoor, A., Okon, Y., Pines, O., and Prusky, D. 2003. A combination of external $\mathrm{pH}$ and nitrogen assimilation affect secretion of the virulence factor pectate lyase by $C$. gloeosporioides. Appl. Environ. Microbiol. 69:3258-3262.

Eshel, D., Miyara, I., Ailing, T., Dinoor, A., and Prusky, D. 2002. pH regulates endoglucanase expression and virulence of Alternaria alternata in persimmon fruits. Mol. Plant-Microbe Interact. 15:774-779.

Guindon, S., and Gascuel, O. 2003. A simple, fast, and accurate algorithm to estimate large phylogenies by maximum likelihood. Syst. Biol. 52:696-704.

Hadas, Y., Goldberg, I., Pines, O., and Prusky, D. 2007. Involvement of gluconic acid and glucose oxidase in the pathogenicity of Penicillium expansum in apples. Phytopathology 97:384-390.

Hong, X. 1998. Identification of major phylogenetic branches of inhibitory ligand-gated channel receptors. J. Mol. Evol. 47:323-333.

Horowitz, S., Freeman, S., and Sharon, A. 2002. Use of green fluorescent protein-transgenic strains to study pathogenic and nonpathogenic lifestyles in Colletotrichum acutatum. Phytopathology 92:743-749.

Javelle, A., Lupo, D., Zheng, L., Li, X. D., Winkler, F. K., and Merrick, M. 2006. An unusual twin-His arrangement in the pore of ammonia channels is essential for substrate conductance. J. Biol. Chem. 281:3949239498.

Javelle, A., Lupo, D., Ripoche, P., Fulford, T., Merrick, M., and Winkler, F. K. 2008. Substrate binding, deprotonation, and selectivity at the periplasmic entrance of the Escherichia coli ammonia channel AmtB. Proc. Natl. Acad. Sci. U.S.A. 105:5040-5045.

Karaffa, L., and Kubicek, C. P. 2003. Aspergillus niger citric acid accumulation: Do we understand this well working black box? Appl. Microbiol. Biotechnol. 1:189-196.

Khademi, S., O’Connell, J. I., Remis, J., Robles-Colmenares, Y., Miercke, L. J., and Stroud, R. M. 2004. Mechanism of ammonia transport by Amt/MEP/Rh: Structure of AmtB at 1.35 A. Science 305:1587-1594.

Kramer-Haimovich, H., Servi, E., Katan, T., Rollins, J., Okon, Y., and Prusky, D. 2006. Effect of ammonia production by Colletotrichum gloeosporioides on pelB activation, pectate lyase secretion, and fruit pathogenicity. Appl. Environ. Microbiol. 72:1034-1039.

Krastel, K., Senadheera, D. B., Mair, R., Downey, J. S., Goodman, S. D., and Cvitkovitch, D. G. 2010. Characterization of a glutamate transporter operon, glnQHMP, in Streptococcus mutans and its role in acid tolerance. J. Bacteriol. 192:984-993.

Linton, K. J., and Higgins, C. F. 1998. The Escherichia coli ATP-binding cassette (ABC) proteins. Mol. Microbiol. 28:5-13.

Magasanki, B., and Kaiser, C. A. 2002. Nitrogen regulation in Saccharomyces cerevisiae. Gene 290:1-18.
Manteau, S., Abouna, S., Lambert, B., and Legendre, L. 2003. Differential regulation by ambient $\mathrm{pH}$ of putative virulence factor secretion by the phytopathogenic fungus Botrytis cinerea. FEMS (Fed. Eur. Microbiol. Soc.) Microbiol. Ecol. 43:359-366.

Miyara, I., Shafran, H., Kramer-Haimovich, H., Rollins, J., Sherman. A., and Prusky, D. 2008. Multifactor regulation of pectate lyase secretion by Colletotrichum gloeosporioides pathogenic on avocado fruits. Mol. Plant Pathol. 9:281-291.

Miyara, I., Davidzon, M., Sherman, A., and Prusky, D. 2010. pH regulation of ammonia secretion by Colletotrichum gloeosporioides and its effect on appressorium formation and pathogenicity. Mol. PlantMicrobe Interact. 23:304-316.

Möller, E. M., Bahnweg, G., Sandermann, H., and Geiger, H. H. 1992. A simple and efficient protocol for isolation of high molecular weight DNA from filamentous fungi, fruit bodies, and infected plant tissues. Nucleic Acids Res. 20:6115-6116.

Nakanishi, S., and Masu, M. 1994. Molecular diversity and functions of glutamate receptors. Annu. Rev. Biophys. Biomol. Struct. 23:319-348.

Prusky, D. 1996. Pathogen quiescence in postharvest diseases. Annu. Rev. Phytopathol. 34:413-434.

Prusky, D., and Yakoby, N. 2003. Pathogenic fungi: Leading or led by ambient pH? Mol. Plant Pathol. 4:509-516.

Prusky, D., McEvoy, J. L., Leverentz, B., and Conway, L. S. 2001. Local modulation of host $\mathrm{pH}$ by Colletotrichum species as a mechanism to increase virulence. Mol. Plant-Microbe Interact. 14:1105-1113.

Prusky, D., McEvoy, J. L., Saftner, R., Conway, W. S., and Jones, R. 2004. The relationship between host acidification and virulence of Penicillium spp. on apple and citrus fruit. Phytopathology 94:44-51.

Ren, Q., and Paulsen, I. T. 2005. Comparative analyses of fundamental differences in membrane transport capabilities in prokaryotes and eukaryotes. PLoS Comp. Biol. 1:e27.

Robinson, M., and Sharon, A. 1999. Transformation of the bioherbicide Colletotrichum gloeosporioides $\mathrm{f}$. sp. aeschynomene by electroporation of germinated conidia. Curr. Genet. 36:98-104.

Rollins, J. A., and Dickman, M. B. 2000. pH signaling in Sclerotinia sclerotiorum: Identification of a pacC/RIM1 homolog. Appl. Environ. Microbiol. 67:75-81.

Rutherford, J. C., Chua, G., Hughes, T., Cardenas, M. E., and Heitman, J. 2008. A Mep2-dependent transcriptional profile links permease function to gene expression during pseudohyphal growth in Saccharomyces cerevisiae. Mol. Biol. Cell 19:3028-3039.

Ryan, R. M., Compton, E. L., and Mindell, J. A. 2009. Functional characterization of a $\mathrm{Na}^{+}$-dependent aspartate transporter from Pyrococcus horikoshii. J. Biol. Chem. 284:17540-17548.

Sato, Y., Noji, S., Suzuki, R., and Taniguchi, S. 1989. Dual mechanism for stimulation of glutamate transport by potassium ions in Streptococcus mutans. J. Bacteriol. 171:4963-4966.

Schönig, B. T., Brown, D. W., Oeser, B., and Tudzynski, B. 2008. Crossspecies hybridization with Fusarium verticillioides microarrays reveals new insights into Fusarium fujikuroi nitrogen regulation and the role of AreA and NMR. Eukaryot. Cell 7:1831-1846.

Shafran, H., Miyara, I., Eshed, R., Prusky, D., and Sherman, S. 2008. Development of new tools for studying gene function in fungi based on the Gateway system. Fungal Genet. Biol. 45:1147-1154.

Soupene, E., Ramirez, R. M., and Kustu, S. 2001. Evidence that fungal MEP proteins mediate diffusion of the uncharged species NH3 across the cytoplasmic membrane. Mol. Cell Biol. 21:5733-5741.

Tea Kim, Y., Prusky, D., and Rollins, J. A. 2007. An activating mutation of the Sclerotinia sclerotiorum pacl gene increases oxalic acid production at low pH but decreases virulence. Mol. Plant Pathol. 8:611-622.

Teichert, S., Rutherford, J. C., Wottawa, M., Heitman, J., and Tudzynski, B. 2008. Impact of ammonium permeases mepA, mepB, and mepC on nitrogen-regulated secondary metabolism in Fusarium fujikuroi. Eukaryot. Cell 7:187-201.

ten Have, A., Beuil, W. O., Wubben, J. P., Visser, J., van Kan, J. A. L. 2001. Botrytis cinerea endopolygalacturonase genes are differentially expressed in various plant tissues. Fungal Genet. Biol. 33:97-105.

Ter-Hovhannisyan, V., Lomsadze, A., Chernoff, Y., and Borodovsky, M. 2008. Gene prediction in novel fungal genomes by ab initio algorithm with unsupervised training. Genome Res. 18:1979-1990.

Tolner, B., Ubbink-Kok, T., Poolman, B., and Konings, W. N. 1995. Cation-selectivity of the L-glutamate transporters of Escherichia coli, $\mathrm{Ba}$ cillus stearothermophilus and Bacillus caldotenax: Dependence on the environment in which the proteins are expressed. Mol. Microbiol. 18:123-133.

Winkler, F. K. 2006. Amt/MEP/Rh proteins conduct ammonia. Pfluegers Arch. 451:701-707.

Wipf, D., Benjdia, M., Tegeder, M., and Frommer, W. B. 2002. Characterization of a general amino acid permease from Hebeloma cylindrosporum. FEBS (Fed. Eur. Biochem. Soc.) Lett. 528:119-124. 
Wubben, J. P., ten Have, A., van Kan, J. A. L., and Visser, J. 2000. Regulation of endopolygacturonase gene expression in Botrytis cinerea by galacturonic acid, ambient $\mathrm{pH}$ and carbon catabolite repression. Curr. Genet. 37:152-157.

Yakoby, N., Beno-Moualem, D., Keen, N. T., Dinoor, A., Pines, O., and Prusky, D. 2001. Colletotrichum gloeosporioides pelB, is an important factor in avocado fruit infection. Mol. Plant-Microbe Interact. 14:988995.

Yernol, D., Boudker, O., Jin, Y., and Gouaux, E. 2004. Structure of glutamate transporter homologue from Pyrococcus horikoshii. Nature 431:811-818.
Zheng, L., Kostrewa, D., Bernèche, S., Winkler, F. K., and Li, X. D. 2004 The mechanism of ammonia transport based on the crystal structure of AmtB of E. coli. Proc. Natl. Acad. Sci. U.S.A. 101:17090-17095.

Zientz, E., Dandekar, T., and Gross, R. 2004. Metabolic interdependence of obligate intracellular bacteria and their insect hosts. Microbiol. Mol. Biol. Rev. 68:745-770.

\section{AUTHOR-RECOMMENDED INTERNET RESOURCE}

Broad Institute website: www.broadinstitute.org 